\title{
Efecto de la crisis financiera (2007-2010) en la innovación estratégica y la estructura productiva en el proceso de formación de los precios *
}

\author{
Impact of financial crisis (2007-10) \\ in strategic innovation and production \\ structure in the asset pricing process
}

\author{
Alfredo Juan Grau Grau ** . Universidad de Valencia
}

\begin{abstract}
RESUMEN El objetivo de este trabajo es analizar en qué medida los factores asociados a la estructura productiva e innovación estratégica de la empresa, influyen en el proceso de valoración de los rendimientos de activos financieros. La literatura no proporciona estudios que traten estos factores en el proceso de valoración y, por tanto, la escasez de los mismos no ofrece resultados concluyentes en las plazas estudiadas. Nuestros resultados subrayan, por un lado, la destacada relevancia de la capacidad productiva en la formación del precio y, por otro, la escasa influencia de aquellos parámetros que definen la capacidad de innovar. Una valoración de los activos financieros españoles con modelos que solo consideran el riesgo de mercado supondría sobrevalorar un gran número de las carteras consideradas. El proceso de consolidación del Euro y la llegada de la crisis de 2007, ha provocado que los impactos de sobrevaloración se agudicen considerablemente.
\end{abstract}

PALABRAS CLAVE Modelos de valoración de activos; Primas de riesgo; Primas económicas; Estructura productiva e innovación estratégica; Adopción del Euro; Crisis de 2007.

\begin{abstract}
The aim of this paper is to analyze the extent to which factors associated with the structure of production and corporate innovation strategies influence in asset pricing process. The literature not provided studies that examine these factors in the assessment process and, therefore, the shortage of them does not provide conclusive results in the markets studied. Our results highlight the one hand, the relevance of productive capacity in asset pricing and, secondly, the reduced influence of the parameters that define the ability to innovate. An assessment of Spanish financial assets models which only consider the market risk would overestimate a large number of portfolios considered. The consolidation Euro process and the arrival of the 2007 crisis, has caused higher impacts of overvaluation.
\end{abstract}

KEYWORDS Asset pricing models; Risk premia; Economic premias; Structure of production and innovation strategy; Euro; 2007 financial crisis.

\footnotetext{
* Agradecimientos: El autor agrade la ayuda y los valiosos consejos de la Doctora M. ${ }^{2}$ Begoña Font Belaire de la Universidad de Valencia. Se agradecen también las propuestas de mejora y sugerencias vertidas por los evaluadores anónimos, así como al editor de la revista. Una versión previa de este artículo está publicada como documento de trabajo n. ${ }^{\circ}$ 613/2011 en FUNCAS.

** Autor para la correspondencia: Alfredo Juan Grau Grau, Departamento de Finanzas Empresariales, Universidad de Valencia, Avda. de los Naranjos, s/n, 46022 Valencia, España. Tel +34961625343. Correo electrónico: alfredo.grau@uv.es
} 


\section{INTRODUCCIÓN}

El estudio de las distintas fuentes de riesgo que participan activamente en la formación del precio de los activos financieros, ha suscitado desde hace muchas décadas un destacado interés que sigue vigente en nuestros días. A lo largo de la extensa literatura se han ido incorporando otros muchos factores explicativos además del conocido riesgo de mercado, citemos por ejemplo, el efecto tamaño ${ }^{(1)}$ (capitalización), efecto ratio book-to-market ${ }^{(2)}$, y efecto momentum ${ }^{(3)}$.

En la búsqueda de nuevos parámetros explicativos de los rendimientos de los activos cotizados, encontramos el trabajo de Vassalou y Apedjinou (2004) a través del cual intentan justificar la relevancia de nuevas variables que proporcionen una adecuada capacidad explicativa. Aportan evidencias empíricas que defienden que la dotación de los factores capital y trabajo podrían ser elementos clave, aunque insuficientes, para explicar las variaciones de los beneficios brutos empresariales y consecuentemente la variación de los rendimientos de los activos financieros. Del mismo modo, Rodríguez et al. (2009) insisten en aseverar que las infraestructuras empresariales tienen una influencia relevante en la producción.

Desde la óptica de la teoría económica, en general, y desde el punto de vista de los estrategas, en particular, se coincide en afirmar que disponer de la misma cantidad de capital y trabajo no es suficiente para replicar los resultados en términos de cuota de mercado y los resultados económicos. Identificar otros factores que potencialmente podrían jugar un papel activo, podría ser de relevante interés, a saber: los esfuerzos realizados en materia de marca, la calidad de la gestión corporativa y el grado de compromiso con la innovación, entre otros (véase González y Ventura, 2007). Estos factores podrían ser el componente que mide las variaciones de los beneficios brutos que no explican las variaciones de las inversiones en capital y mano de obra (inversión en trabajo). Se puede comprobar que empresas que ostentan la misma dotación de capital y trabajo pueden conducir a niveles de beneficios brutos bastante heterogéneos. Atendiendo a los argumentos expuestos en este trabajo, el volumen de capital y trabajo conformarían la capacidad productiva de la empresa que llamaremos factores asociados a la estructura productiva (FREP); por otro lado, el segundo grupo de parámetros que no están incluidos en el primero y que hacen referencia a la capacidad de innovar de las organizaciones, los llamaremos factores de innovación estratégica (FRIE) (véase Vassalou y Apedjinou, 2004). Ambos factores en su conjunto, también son conocidos como factores «condiciones de negocio» ${ }^{(4)}$.

(1) Véanse, entre otros, Banz (1981) para el mercado americano, Hawawini y Kein (1995) para varios mercados internacionales y Rubio (1988) para el mercado de capitales español.

(2) Véanse, por ejemplo, Stattman (1980) y Fama y French $(1992,1993)$ para el mercado americano, Fama y French (1998) para una selección internacional de mercados, y Menéndez (2000) y Miralles y Miralles (2003) para el mercado de capitales español.

(3) Véanse, particularmente, DeBondt y Thaler (1985), y Moskowitz y Grinblatt (1999), para el mercado americano, y por Forner y Marhuenda $(2003,2006)$ para el mercado de capitales español.

(4) González y Ventura (2007) denominan a este factor «variedad estratégica», y queda definido por los factores intensidad de capital (estrategia de producción), gastos en publicidad (estrategia de marketing) y gastos en I+D (estrategia de innovación). Señalan que la elección de estas variables viene justificada por su capacidad para aproximar de una manera razonable las dimensiones más importantes de la estrategia empresarial. 
A la luz de los planteamientos anteriores, nos preguntamos si esta variedad de factores contienen información significativa en materia de valoración, y consecuentemente, explican las variaciones de los rendimientos de los activos financieros. De esta forma, perfilamos el objetivo de este trabajo que consiste en cuantificar la contribución de los factores asociados a la estructura productiva (FREP) y factores asociados a la innovación estratégica (FRIE) a través de la estimación y contrastación de varios modelos de valoración. Cabe señalar que el período de estudio registra acontecimientos muy destacados: desde la creación del mercado único, adopción del Euro, programas de estabilidad, varios tratados (Tratado de Amsterdam, Tratado de Niza, Tratado Lisboa, etc.), hasta la crisis de 2007; proporcionando así una buena oportunidad para valorar sus consecuencias directas sobre la evolución en las rentabilidades de los títulos cotizados, a través de la consideración de estos factores propuestos. Para ello, escindimos la muestra en subperíodos para poder separar la influencia de estos hechos económicos.

Parte de la motivación de este estudio radica en la ausencia de trabajos de investigación que estudien la influencia de estos factores a través de un modelo de valoración, consultados a lo largo de la extensa literatura financiera para el mercado de capitales español. Es más, no existen artículos que desarrollen esta temática a la par que estudien el efecto de la llegada del Euro y la crisis de 2007.

La contribución empírica de este artículo respecto a otros estudios es cuantiosa: (i) la separación de la muestra en tres subperíodos clave que estudian la influencia del establecimiento y consolidación de la moneda única, el Euro, y la crisis que se inició en el año 2007 en el proceso de formación de los precios de los activos arriesgados; (ii) la cuantificación, en general, de los factores en cada uno de los modelos, en términos de primas al riesgo y del impacto económico (premia) si omitiéramos estos nuevos factores para explicar los rendimientos de sección cruzada, para los tres subperíodos y período completo, y (iii) la cuantificación, en particular, de la contribución en los rendimientos de los factores asociados a la estructura productiva y a la innovación estratégica, considerando los tres subperíodos y período completo.

Este trabajo parte de los estudios de Vassalou y Apedjinou (2004) ${ }^{(5)}$ fundamentalmente en la elección de los factores considerados, FREP y FRIE, y su correspondiente procedimiento de construcción. La medición del impacto de las primas económicas se desarrolla, entre otros, siguiendo la metodología proporcionada en los trabajos de De Santis, Gerard y Hillion (2003) ${ }^{(6)}$. El proceso de estimación y contrastación de los modelos que integran los factores expuestos y la medición del impacto de las primas económicas, a nuestro entender es de relevante importancia para profundizar y llegar a proporcionar evidencias y conclusiones relevantes. Para el mercado de capitales español no se ha estudiado ningún modelo de valoración que integre estos factores y mucho menos se han analizado el impacto económico, a través del estudio de las premias.

Estos argumentos reseñan que la literatura publicada para el mercado de capitales español, en materia de valoración, no aborda estudios que incorporen la influencia

(5) Su estudio incorpora empresas para el mercado americano (NYSE, AMEX y NASDAQ).

(6) Desarrolla su trabajo para diez países pertenecientes a varios mercados internacionales: Austria, Bélgica, Francia, Alemania, Italia, Japón, Países Bajos, España, Reino Unido y Estados Unidos. Nótese que el estudio del impacto de las premias, De Santis, Gerard y Hillion (2003), Io aplican para medir el grado de integración europea y no para el estudio sobre los factores propuestos en este artículo. 
de las decisiones estratégicas en el proceso de formación de los precios de los activos financieros. Esto último, y el estudio de los impactos de las premias, es lo que encontramos también a faltar, en general, para nuestro mercado; y en particular, en la metodología expuesta en Vassalou y Adpedjinou (2004).

Los resultados obtenidos se pueden resumir de la siguiente manera: (i) los riesgos asociados a la estructura productiva y a la innovación estratégica contribuyen a la explicación de las variaciones de los rendimientos medios de los activos financieros en sección cruzada; (ii) aunque el modelo de Fama y French (1993) con factor momentum (negociación), sigue siendo el modelo que mejor ajusta para el período completo, atendiendo a los subperíodos el modelo «condiciones de negocio» es el que facilita errores de estimación más reducidos; y (iii) se registran impactos económicos a través de los factores considerados desvelando el peligro de sobrevaloración de los rendimientos de nuestros activos si se omiten los mismos para las agrupaciones sector y tamaño-BM.

Los restantes apartados del artículo se organizan en los siguientes términos. En el apartado 2 presentamos los datos y explicamos la construcción de las carteras y de los factores. En el apartado 3 describimos los modelos de valoración empleados en el estudio y exponemos la metodología aplicada. En el apartado 4 detallamos los resultados empíricos del artículo: la contribución de los factores de los modelos en términos de primas al riesgo y primas económicas. Y con el apartado 5 concluimos con un resumen de los resultados y conclusiones más importantes.

\section{DATOS, CONSTRUCCIÓN DE CARTERAS Y FACTORES}

Proporcionamos en este apartado los resultados estadísticos basados en los rendimientos totales mensuales ajustados por dividendos de los activos individuales cotizados en el mercado de capitales continuo español, agrupados en dos categorías de carteras: por sector ${ }^{(7)}$ y clasificadas por tamaño y ratio book-to-market (tamaño-BM) para una muestra que se inicia en enero de 1993 y finaliza en diciembre de 2010. En el presente, facilitamos los datos utilizados y las carteras construidas, los correspondientes factores de riesgo y las variables de estado (medidoras de la evolución del ciclo económico).

\subsection{DAtos}

Hemos calculado los rendimientos mensuales totales netos de los activos individuales tomando las series de precios diarios a cierre corregidos por ampliaciones de capital, reducciones de capital y datos de dividendos obtenidos en la plataforma INTERTELL. Hemos agregado los datos correspondientes a las empresas que cotizaron durante el periodo de estudio. Eliminamos aquellas empresas que dejaron de cotizar o fueron excluidas por el propio mercado, para poder así actualizar nuestra base. Los rendimientos los hemos calculado usando las cotizaciones del último día del mes corregidas por dividendos netos (dividendo anual bruto corregido por impuestos usando la corrección propuesta por SToxx para España, distribuido uniformemente entre los doce meses). Finalmente disponíamos de 132 activos, una vez suprimidos aquellos que no arrojaban información sobre dividendos.

(7) El trabajo de González y Ventura (2007) considera únicamente una agrupación sectorial. Coincidimos en estudiar cómo afectan estas variables «de innovación» a la rentabilidad de los activos, en su caso sobre el sector industrial, y en el nuestro, todos los sectores de la economía. 
Para calcular la cartera de mercado utilizamos las series del índice Ibex-35 e Ibex-35 con dividendos obtenidos a través de la Sociedad DE Bolsas; y el tipo medio de operaciones con pacto de recompra a un año en letras y bonos facilitado por el Banco de España, para calcular los excesos de los rendimientos respecto a la tasa libre de riesgo. La variable de estado ratio dividendo-precio (div) la calculamos a partir de las series del índice Ibex-35 e Ibex-35 con dividendos, y la variable de estado diferencial de tipos (term) a partir de los tipos medios de letras y bonos a un y de bonos a 4-5 años facilitados por el Banco de España. Finalmente, los datos contables para obtener las series de resultados por estructura productiva, por innovación estratégica y resto de factores (tamaño, ratio book-to-market y momentum); así como el cálculo de las carteras clasificadas por tamaño y ratio book-to-market, se extraen esencialmente de SABI e INTERTELL y se complementan con la información contable detallada en las webs correspondientes de las Bolsas de Madrid, Barcelona y Valencia.

\subsection{CONSTRUCCIÓN DE LAS CARTERAS Y FACTOR MERCADO}

La agrupación sectorial contiene seis carteras correspondientes a seis sectores (energía, industria, bienes, servicios, financiero y tecnológico). Los activos se asignan a cada una de las carteras según esta naturaleza y se ponderan por capitalización ${ }^{(8)}$, de modo que el peso asignado a cada activo se actualiza mensualmente y es igual al cociente del promedio para el mes anterior de la capitalización de cada activo sobre el total de promedios mensuales del sector al que pertenece. La otra agrupación, tamaño-BM, está formada por nueve carteras ordenadas de menor a mayor tamaño y ratio book-to-market ${ }^{(9)}$ siguiendo el procedimiento de Fama y French (1993). La composición de las carteras se actualiza mensualmente con los datos provenientes del mes anterior ordenando los activos de menor a mayor promedio de capitalización y paralelamente de menor a mayor promedio ratio book-to-market. Seguidamente, se forman tres clases de (aproximadamente) igual número de activos, esto es, baja (L), media (M) y alta $(\mathrm{H})$; siendo el peso de cada activo en su cartera proporcional al número de activos que forma parte de la misma. Moskowiz y Grinblatt (1999) encuentran un componente específico momentum a nivel industria y ello hace pensar que ciertos efectos pueden ser característicos de algunos sectores, de ahí la justificación de la primera agrupación; captando así, el diferente impacto de los distintos efectos que se pueden observar por la pertenencia a un determinado sector. Por otro lado, la segunda agrupación, atendiendo a las evidencias vertidas, entre otros, por Conrad, Gultekin y Kaul (1991) que argumentan que se puede predecir la volatilidad condicional asimétrica que se pueden dar entre empresas grandes y empresas pequeñas, manifestando así la relevancia del volumen de capitalización de las mismas.

La tabla 1 (paneles A y B) muestra los estadísticos descriptivos para las dos agrupaciones de carteras, destaquemos: (i) el rechazo de la hipótesis de normalidad (al 5\%) para todas las carteras sectoriales y todas las carteras tamaño-BM, y (ii) la escasez de estructuras dinámicas $^{(10)}$ significativas (al 5\%) en medias y varianzas para 6, 12 y 24 retardos.

(8) En la construcción de estas carteras sectoriales ponderamos por volumen de capitalización ya que se busca una medida de la rentabilidad del sector y por tanto pueden estar incorporadas empresas muy pequeñas así como muy grandes.

(9) No consideramos los ratios book-to-market negativos, por tanto no se hizo el promedio con ellos.

(10) Dada la ausencia de estructuras dinámicas en las series de los rendimientos, descartamos la aplicación de la metodología de estimación y contraste GARCH en la valoración de los activos financieros. 


\section{TABLA 1}

Estadísticos descriPTivos PARA LAS CARTERAS POR SECTOR Y TAMAÑo-BM

\begin{tabular}{|c|c|c|c|c|c|c|}
\hline \multicolumn{7}{|c|}{ Panel A: Carteras por Sector } \\
\hline Sector & Media & $D S$ & $J B$ & $Q(6)$ & $Q(12)$ & $Q(24)$ \\
\hline ENERGÍA & 0.015416 & 0.056757 & $57.67971^{\star *}$ & 60.440 & 90.807 & 185.731 \\
\hline INDUSTRIA & 0.012489 & 0.074012 & $13.04517^{* *}$ & 68.509 & 158.201 & $36.169^{\wedge}$ \\
\hline BIENES & 0.014172 & 0.056871 & $41.52205^{\star *}$ & 73.068 & 172.141 & $36.202^{\wedge}$ \\
\hline SERVICIOS & 0.020008 & 0.076742 & $409.2172^{* *}$ & 26.108 & 73.910 & 158.454 \\
\hline FINANCIERO & 0.015401 & 0.050889 & $7.520876^{*}$ & 78.670 & 141.074 & 226.294 \\
\hline \multirow[t]{2}{*}{ TECNOLÓGICO } & 0.023124 & 0.119749 & $6.247999^{*}$ & 98.045 & 148.314 & 242.444 \\
\hline & $Q^{2}(6)$ & $Q^{2}(12)$ & $Q^{2}(24)$ & & & \\
\hline ENERGÍA & 47.333 & 75.748 & 169.791 & & & \\
\hline INDUSTRIA & $20.534^{* *}$ & $27.864^{* *}$ & 288.201 & & & \\
\hline BIENES & 86.928 & 113.901 & 161.621 & & & \\
\hline SERVICIOS & 16.474 & 23.905 & 56.993 & & & \\
\hline FINANCIERO & $24.961^{* *}$ & $46.413^{* *}$ & $53.900^{* *}$ & & & \\
\hline TECNOLÓGICO & $18.425^{* *}$ & $29.479^{* *}$ & $49.126^{*}$ & & & \\
\hline
\end{tabular}

\begin{tabular}{|c|c|c|c|c|c|c|}
\hline \multicolumn{7}{|c|}{ Panel B: Carteras por Tamaño-BM } \\
\hline Tam-book & Media & $D S$ & $J B$ & $Q(6)$ & $Q(12)$ & $Q(24)$ \\
\hline LL & 0.015163 & 0.061463 & $8.745741^{*}$ & 2.35591 & 10.04501 & 13.79851 \\
\hline$L M$ & 0.010353 & 0.095548 & $2645.835^{\star * *}$ & 6.04931 & 6.80911 & 15.60151 \\
\hline$L H$ & 0.012219 & 0.062070 & $14.02983^{* *}$ & 3.58311 & 8.52481 & 16.12251 \\
\hline$M L$ & 0.012675 & 0.064116 & $395.1328 *$ & 7.43731 & 15.24151 & $35.272^{\wedge}$ \\
\hline MM & 0.012094 & 0.094399 & $317.8537^{* *}$ & 3.0475 & 13.7829 & 25.2619 \\
\hline$M H$ & 0.009675 & 0.072752 & $51.40046 *$ & 3.4268 & 11.7489 & 28.6759 \\
\hline$H L$ & 0.012028 & 0.057672 & $15.14457^{\star *}$ & 10.7139 & 18.5169 & $37.1339^{*}$ \\
\hline$H M$ & 0.005934 & 0.078306 & $43.54766^{* *}$ & 2.8012 & 6.5588 & 18.8459 \\
\hline \multirow[t]{2}{*}{$H H$} & 0.013594 & 0.063755 & $39.03159^{* *}$ & 12.0539 & 18.2809 & 26.7679 \\
\hline & $Q^{2}(6)$ & $Q^{2}(12)$ & $Q^{2}(24)$ & & & \\
\hline$L L$ & 11.1949 & 16.6519 & 23.3759 & & & \\
\hline$L M$ & 1.3518 & 1.7235 & 19.4789 & & & \\
\hline$L H$ & 39.1969 & 59.3549 & 19.5009 & & & \\
\hline$M L$ & 1.6792 & 26.6959 & 11.3739 & & & \\
\hline MM & 65.6789 & 92.4379 & 16.8329 & & & \\
\hline$M H$ & 2.2216 & 92.4076 & 10.5136 & & & \\
\hline$H L$ & $44.045^{\star \star}$ & $74.7556^{\star \star}$ & $80.9376^{\star *}$ & & & \\
\hline$H M$ & $16.2806^{* *}$ & $18.2016^{\wedge}$ & 20.9886 & & & \\
\hline$H H$ & $12.5416^{\star}$ & $18.2466^{\wedge}$ & 24.3866 & & & \\
\hline
\end{tabular}

La tabla presenta en los Paneles A y B los siguientes estadísticos descriptivos para las carteras sectoriales y tamaño-BM, respectivamente: el valor medio de los rendimientos. Su desviación estándar (DS) y el test de Jarque-Bera $\left(H_{0}\right.$ : Normalidad). Se proporcionan los correlogramas para 6, 12 y 24 retardos (contraste $Q$ de Lung-Box) para el estudio de las dinámicas de la media $(Q(\cdot))$ y para estudiar las dinámicas de las varianzas $\left(Q^{2}(\cdot)\right)$. Nivel de significatividad de los contrastes: $10 \%{ }^{(\wedge)} ; 5 \%^{(*)}$ y $1 \%{ }^{(* *)}$. 


\section{GrÁFICA 1}

REPRESENTACIÓN DE LOS ERRORES DE ESTIMACIÓN PARA LOS MODELOS MEP Y MCN DEL PERÍODO COMPLETO

Panel A: Carteras por Sector

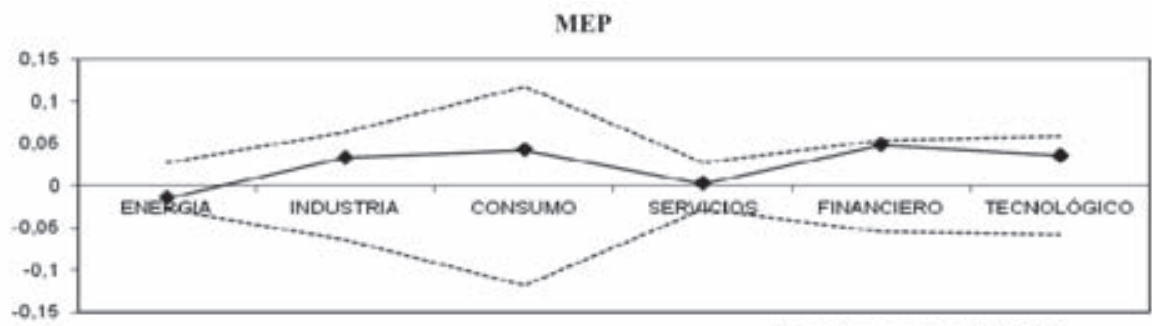

Error de estimación: 0.087985

$\mathrm{MCN}$

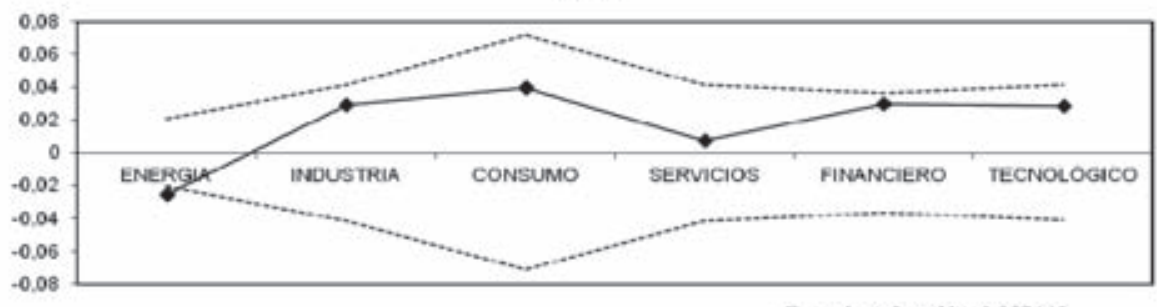

Error de estimación: 0,057445

Panel B: Carteras por Tamaño-BM
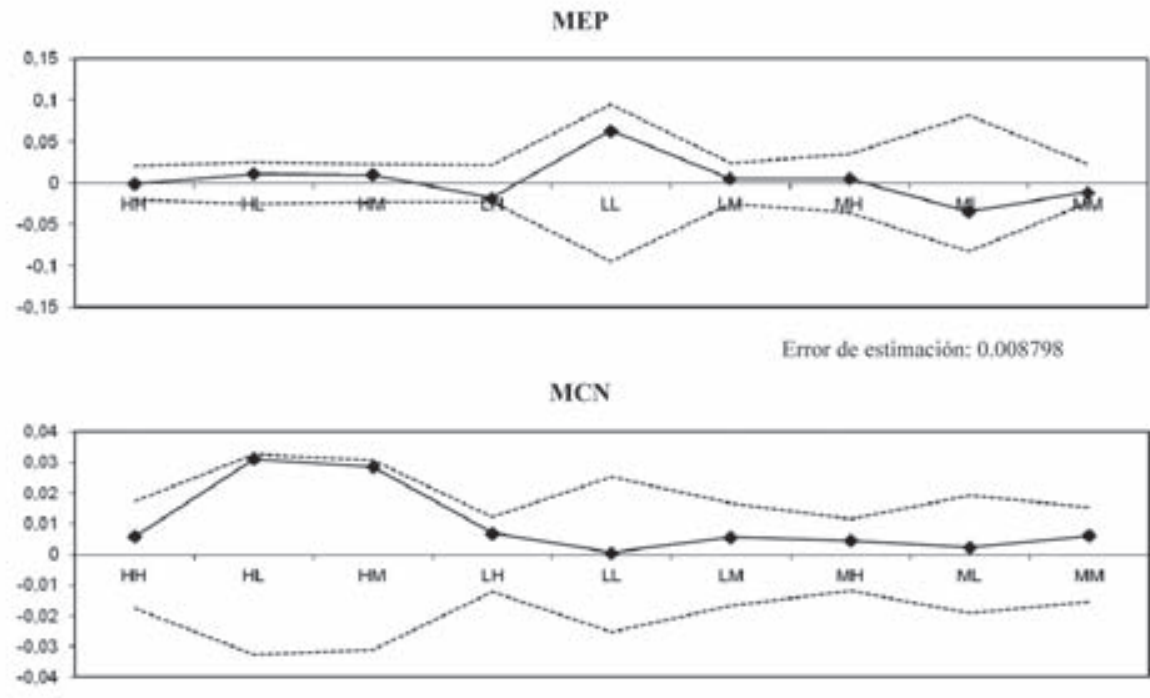

Error de estimación: 0.009778

La gráfica representa los errores de estimación de los modelos MEPy MCN junto con la banda de confianza \pm 2 desviaciones típicas del error de estimación para las dos agrupaciones de carteras. 
Adicionalmente calculamos los factores de riesgo de mercado (EXM), y dos variables de estado ratio dividendo-precio (div) y diferencial de tipos (term). Para obtener el factor EXM diferenciamos los rendimientos mensuales totales de la cartera de mercado (índice Ibex-35) con el activo libre de riesgo (tipo medio de operaciones con pacto de recompra a un año en letras y bonos). Dado que en el presente trabajo se asumen modelos de valoración condicionales, para introducir en éstos la información cambiante sobre el ciclo económico precisamos calcular variables de estado que nos midan este efecto (véase, por ejemplo, Fama y French, 1988, 1989; Cohrane, 1996; y Ferson y Harvey, 1991, 1999). Particularmente elaboramos el ratio dividendo-precio (div) y el diferencial tipos a corto y medio/largo plazo (term). La variable de estado div la calculamos a partir de las series del índice Ibex-35 e Ibex-35 con dividendos, corrigiendo los dividendos brutos por impuestos y dividiendo por el precio de cotización, y la variable de estado term restando los tipos medios de bonos de 4-5 años a los tipos de letras y bonos de un año.

\subsection{CONSTRUCCIÓn DE LOS FACTORES ESTRUCTURA PRODUCTIVA E INNOVACIÓN ESTRATÉGICA}

Tal y como hemos introducido, en el seno de la empresa se acometen muchas y variadas decisiones de tipo estratégico las cuales ejercen gran influencia conduciendo así a generar márgenes de beneficios brutos que se esperan cuantiosos. Ello nos conduce a estudiar las potenciales consecuencias que se derivan de los cambios que se producen en estos resultados económicos debidos a la estructura productiva de la empresa y a aquellos que no están incluidos en estos últimos, eso es, la capacidad de innovar o innovación estratégica.

Para construir estos factores hemos seguido las pautas y el procedimiento propuesto en Vassalou y Apedjinou (2004). Este procedimiento se ha adaptado al objetivo de medir ambos factores de riesgo, cuantificar riesgos ortogonales y a los datos contables disponibles para España que son de índole anual. Los factores estructura productiva e innovación estratégica se construyen con el procedimiento que pasamos a detallar. En primer lugar hemos seleccionado las variables contables por empresa y proponemos las siguientes (todas con carácter anual): el resultado bruto de explotación (RBE) para medir los resultados económicos (margen de beneficio bruto), el inmovilizado total $(K)$ como proxie de la inversión en capital (factor capital) y los gastos de personal $(L)$ como proxie de la inversión en el factor trabajo. Como es lógico se han registrado valores negativos para la variable $R B E$, los cuales se han eliminado ${ }^{(11)}$. También hemos detectado ausencias de datos o cuyo valor era cero para $K$ y/o $L$ y por tanto se ha procedido a suprimirlos de la base. Para obtener un resultado más robusto se procedió a eliminar los datos extremos que pudieran enmascararlo y por tanto, tomamos los rendimientos anuales del resultado de explotación $\left(\Delta^{a} R B E\right)$ por encima del percentil del $95 \%$.

En segundo lugar precisamos calcular las series de resultados asociados a la estructura productiva (REP) y asociados a la innovación estratégica (RIE). Para obtenerlas ${ }^{(12)}$

(11) Hemos eliminado los valores negativos de RBE ya que nuestras regresiones se hacen sobre «rendimientos» y por tanto la magnitud, por definición, solo se puede calcular sobre valores positivos. Señalar que los datos contables se toman del balance a $31 / 12$ del año $t$ para calcular los valores de $t+1$.

(12) Aunque no pretendemos aquí dar una justificación teórica para la medida de la innovación estratégica, cabe destacar que estos desarrollos pueden ser entendidos como una referencia a la función de producción Cobb-Douglas: $Y_{t}=A_{t} K_{t}^{\alpha_{1}}+L_{t}^{\alpha_{2}}$, siendo $Y_{t}$ el valor de la producción de la empresa en $t, K_{t}$ el stock de capital utilizado en $t$ y $L_{t}$, la entrada de mano de obra en el proceso de producción. 
los datos por empresa se clasifican en función del valor de $\Delta^{a} R B E$ en tres categorías: baja (L), media (M) y alta (H) y se estiman las siguientes regresiones en rolling beta (con corrección de heterocedasticidad de White, 1980) por categoría $j, j=L, M, H$ y año $t, t=$ Ene-93,... ,Dic-10:

$$
\Delta^{a} R B E_{i t}=\varphi_{j t}+\mu_{j t} \Delta^{a} K_{i t}+\Psi_{j t} \Delta^{a} L_{i t}+e_{i t}, \quad i \in \text { categoría } j
$$

siendo $\Delta^{a} R B E_{i t}=\left(R B E_{i t}-R B E_{i-1}\right) / R B E_{i t-1}, \Delta^{a} K_{i t}=\left(K_{i t}-K_{i-1}\right) K_{K_{i-1}}$ y $\Delta^{a} L_{i t}={ }^{\left(L_{i t}-L_{i t-1}\right)} / L_{i t-1}$. A partir de los coeficientes $\mu_{j t}$ y $\Psi_{j t}$ estimados $\left(\hat{\mu}_{j t} \mathrm{y} \hat{\Psi}_{j t}\right.$ respectivamente) se pueden calcular las variables $R E P_{i t}$ y $R I E_{i t}$ por empresa $i(i \in$ categoría $j)$ y año $t$ haciendo:

$$
\begin{gathered}
R B E_{i t}=\hat{\mu}_{j t} \Delta^{a} K_{i t}+\hat{\Psi}_{j t} \Delta^{a} L_{i t} \\
R I E_{i t}=\Delta^{a} R B E_{i t}-\hat{\mu}_{j t} \Delta^{a} K_{i t}+\hat{\Psi}_{j t} \Delta^{a} L_{i t}
\end{gathered}
$$

La tabla 2: panel A resume los resultados de estas regresiones: $R^{2}$ ajustado y contraste $\chi^{2}(2)$ para analizar la significatividad conjunta de los coeficientes $\mu_{j t} \mathrm{y} \Psi_{j t}, \forall i, \forall t$. Señalemos que, a pesar de la división en tres categorías por años para "agrupar" datos de características similares la calidad de las regresiones no es demasiado buena; es aceptable para, aproximadamente, el $40 \%$ de las regresiones de la categoría L y para el 20\% de las regresiones de las categorías $M$ y $H$.

Finalmente, obtenemos el factor de riesgo asociado a la estructura productiva (FREP) y asociado a la innovación estratégica $(F R I E)$ con el siguiente procedimiento. El factor FREP se cuantifica tomando como referencia la variable REP y ordenándola anualmente de mayor a menor tamaño se subdivide la muestra en tres tramos, obteniéndose así las empresas ganadoras (G) como aquellas que muestran un mayor factor REP, las empresas intermedias (M) que son las que representan los valores centrales de $R E P$ y finalmente, las empresas perdedoras (P) que muestran el tercil con los valores más reducidos para $R E P$. De forma análoga, el factor FRIE se obtiene ordenando de mayor a menor tamaño la variable RIE obteniéndose tres terciles, siendo el primero el que contiene los valores más elevados y asociados a las empresas ganadoras (G), los valores centrales se adjudican a las empresas intermedias (M) y el último tercil, como el representativo de las empresas perdedoras (P). A continuación, calculamos las series de ambos factores como la diferencia entre los promedios de los rendimientos de las carteras ganadoras (G) menos los promedios de los rendimientos de las carteras perdedoras $(\mathrm{P})$.

El panel B de la tabla 2, muestra los resultados descriptivos para estos dos factores. Los rendimientos, en media, son negativos para el factor estructura productiva (FREP) siendo solamente significativo (al 10\%) para el período pre-euro. En cuanto al factor innovación estratégica $(F R I E)$, muestra rendimientos positivos, en media, y además significativos (al 5\%) para el período completo y todos los subperiodos. Para ambos factores se rechaza el test de normalidad para una significatividad al $1 \%$.

Como medida de robustez a los resultados presentados en la estimación de la ecuación (1), adicionalmente la regresamos en serie temporal, tal y como lo hacen Vassalou y Adedjinou (2004). Seguidamente, volvemos a estimar nuestros modelos. Los nuevos 


\section{TABLA 2}

ESTADÍSTICOS DESCRIPTIVOS PARA LOS FACTORES ESTRUCTURA PRODUCTIVA E INNOVACIÓN ESTRATÉGICA

Panel A: Estadísticos para las series por estructura productiva (REP) y por innovación estratégica (RIE)

\begin{tabular}{cccccccccc}
\hline \multirow{2}{*}{ Año } & \multicolumn{3}{c}{ Categoría L } & \multicolumn{3}{c}{ Categoría M } & \multicolumn{3}{c}{ Categoría H } \\
\cline { 2 - 9 } & $R^{2}$ Ajust. & $\chi^{2}(2)$ & Prob. & $R^{2}$ Ajust. & $\chi^{2}(2)$ & Prob. & $R^{2}$ Ajust. & $\chi^{2}(2)$ & Prob. \\
\hline 1993 & $-1.386 \%$ & 3.45043 & 0.1783 & $-4.511 \%$ & 3.09736 & 0.2125 & $9.160 \%$ & 2.16833 & 0.3382 \\
1994 & $-5.784 \%$ & 1.63352 & 0.4544 & $14.144 \%$ & 4.57781 & 0.1014 & $-0.044 \%$ & 4.60996 & 0.0998 \\
1995 & $-3.087 \%$ & 1.70421 & 0.4626 & $4.212 \%$ & 14.7271 & 0.0006 & $8.921 \%$ & 2.27936 & 0.3199 \\
1996 & $11.745 \%$ & 13.9405 & 0.0003 & $3.111 \%$ & 2.54805 & 0.2797 & $-9.922 \%$ & 0.59074 & 0.7443 \\
1997 & $1.199 \%$ & 4.47818 & 0.0982 & $12.650 \%$ & 7.45847 & 0.0240 & $-7.469 \%$ & 1.34565 & 0.5103 \\
1998 & $-7.412 \%$ & 1.01476 & 0.7554 & $-1.429 \%$ & 1.65501 & 0.4371 & $-3.928 \%$ & 2.38977 & 0.3027 \\
1999 & $-1.984 \%$ & 2.57475 & 0.2396 & $4.220 \%$ & 5.87727 & 0.0529 & $38.073 \%$ & 53.5108 & 0.0000 \\
2000 & $38.057 \%$ & 18.5111 & 0.0001 & $5.147 \%$ & 10.0300 & 0.0066 & $3.306 \%$ & 1.98139 & 0.3713 \\
2001 & $-1.824 \%$ & 1.67150 & 0.4815 & $20.066 \%$ & 11.0683 & 0.0039 & $9.165 \%$ & 4.35566 & 0.1133 \\
2002 & $-1.632 \%$ & 3.14784 & 0.2261 & $-7.333 \%$ & 0.03624 & 0.9820 & $-1.669 \%$ & 1.47365 & 0.4786 \\
2003 & $21.436 \%$ & 41.0239 & 0.0000 & $-6.061 \%$ & 0.02535 & 0.9874 & $30.579 \%$ & 160.409 & 0.0000 \\
2004 & $15.655 \%$ & 62.0114 & 0.0000 & $-4.995 \%$ & 3.02798 & 0.2200 & $12.048 \%$ & 4.40116 & 0.1107 \\
2005 & $-7.5124 \%$ & 2.00874 & 0.6574 & $-3.761 \%$ & 1.97451 & 0.3587 & $-1.457 \%$ & 2.04873 & 0.6487 \\
2006 & $13.470 \%$ & 16.7465 & 0.0001 & $1.7847 \%$ & 1.61522 & 0.1758 & $8.645 \%$ & 3.07875 & 0.2974 \\
2007 & $12.874 \%$ & 14.0041 & 0.0005 & $4.3761 \%$ & 5.91623 & 0.0658 & $-5.641 \%$ & 3.18741 & 0.4387 \\
2008 & $3.1541 \%$ & 9.75414 & 0.0784 & $31.784 \%$ & 19.4612 & 0.0043 & $0.945 \%$ & 1.97312 & 0.0257 \\
2009 & $27.874 \%$ & 38.7457 & 0.0000 & $-3.617 \%$ & 2.00472 & 0.3657 & $-8.785 \%$ & 1.47874 & 0.6487 \\
2010 & $-4.8512 \%$ & 1.98745 & 0.5574 & $11.941 \%$ & 13.6192 & 0.0167 & $10.945 \%$ & 12.7874 & 0.0000
\end{tabular}

Panel B.1: Estadísticos para los factores FREP

\begin{tabular}{lcccc}
\hline FREP & completo & pre-euro & $\begin{array}{l}\text { post-euro/ } \\
\text { pre-crisis }\end{array}$ & post-crisis \\
\hline Media & -0.00291 & 0.00177 & -0.00402 & -0.00361 \\
$D S$ & 0.02999 & 0.00678 & 0.01974 & 0.03108 \\
$J-B$ & $121.3012^{* *}$ & $49.4057^{* *}$ & $108.1787^{\star *}$ & $98.7487^{* *}$ \\
$H_{0}: E R=0$ & -1.74517 & $-2.097451^{\wedge}$ & -0.541785 & -0.145874 \\
\hline
\end{tabular}

Panel B.2: Estadísticos para los factores FRIE

\begin{tabular}{lcccc}
\hline FRIE & completo & pre-euro & $\begin{array}{c}\text { post-euro/ } \\
\text { pre-crisis }\end{array}$ & post-crisis \\
\hline Media & 0.010997 & 0.009767 & 0.012707 & 0.008721 \\
$D S$ & 0.03141 & 0.074701 & 0.009273 & 0.010982 \\
$J-B$ & $10.303156^{* *}$ & $21.05871^{* *}$ & $40.70874^{* *}$ & $34.97414^{* *}$ \\
$H_{0}: E R=0$ & $5.14116^{* *}$ & $4.41781^{* *}$ & $2.105788^{*}$ & $1.87451^{*}$ \\
\hline
\end{tabular}

La tabla presenta en el Panel $\mathrm{A}$ el coeficiente de regresión, $R^{2}$, ajustado, el estadístico $\chi^{2}(2)$ y su probabilidad para las tres clasificaciones baja (L),media $(M)$ y alta $(H)$. Estos estadísticos se corresponden con las regresiones para la obtención de las series de resultados por estructura productiva $(R E P)$ y por innovación estratégica (RIE). En los paneles B.1 y B.2 se proporcionan los estadísticos descriptivos para FREP (factor estructura productiva) y FRIE (factor innovación estratégica), respectivamente; el contraste de media igual a cero para los excesos de los rendimientos separado por subperíodos $\left(H_{0}: E R=0\right)$.

Nivel de significatividad de los contrastes: $10 \%{ }^{(\wedge)} ; 5 \%{ }^{(*)} ;$ y $1 \%{ }^{(* *)}$. 


\section{GráFICA 2}

REPRESENTACIÓN DE LOS ERRORES DE ESTIMACIÓN DE LOS MEJORES MODELOS POR SUBPERÍODOS

Panel A: Carteras por Sector

ene-93 a dic-10: FFm

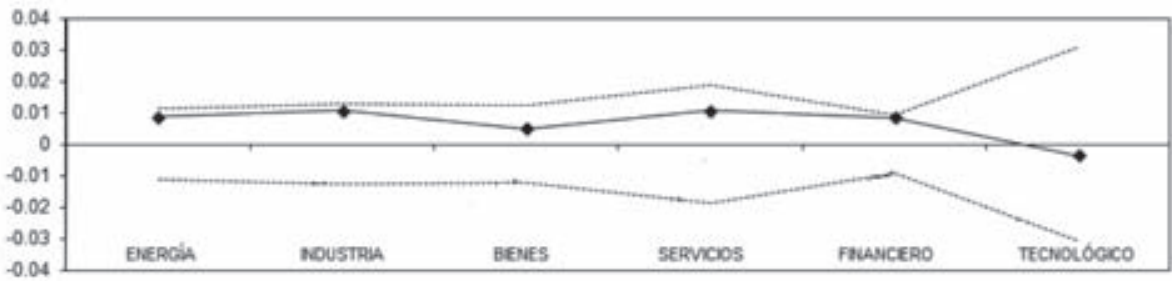

Error de estimación: 0.007415

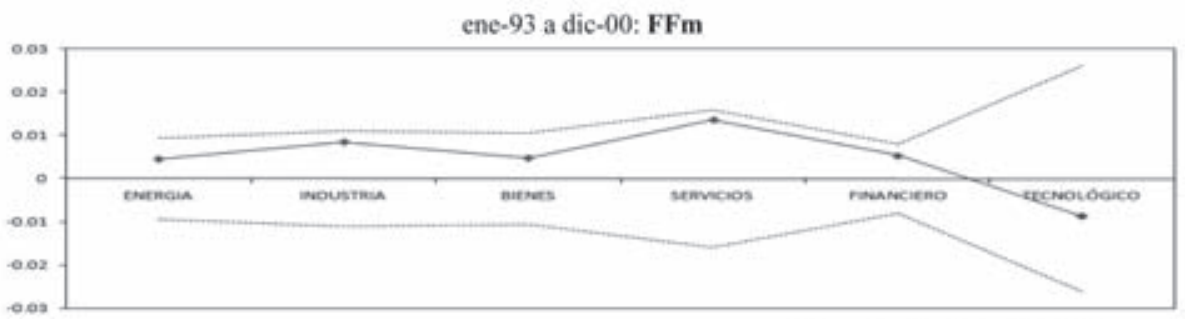

Error de estimación: 0.010767

ene-01 a dic-07: MCN

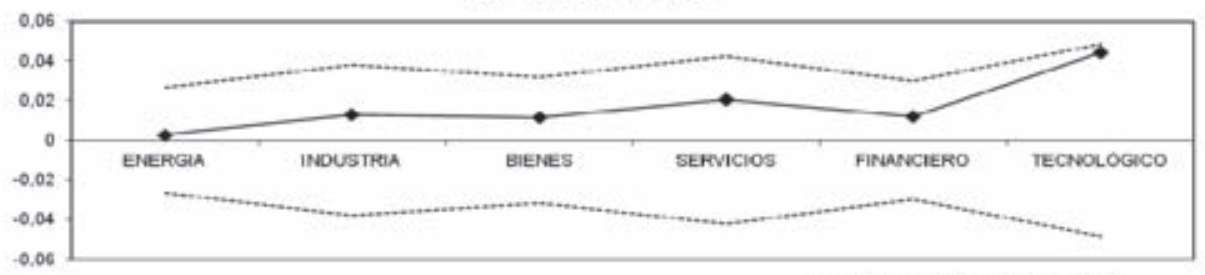

Error de estimación: 0.002449

ene-08 a dic-10: $\mathbf{M C N}$

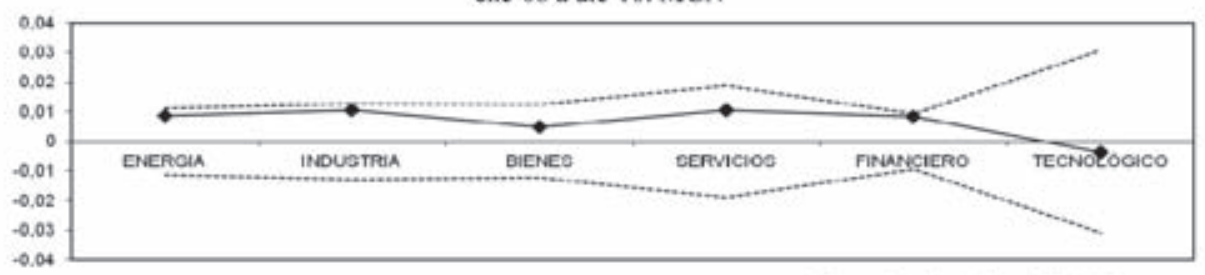

Error de estimación: 0.001857

La gráfica representa los errores de estimación de los mejores modelos junto con la banda de confianza \pm 2 desviaciones típicas del error de estimación para las dos agrupaciones de carteras.

(Continua en la página siguiente) 


\section{GrÁFICA 2 (CONT.)}

REPRESENTACIÓN DE LOS ERRORES DE ESTIMACIÓN DE LOS MEJORES MODELOS POR SUBPERÍODOS

Panel B: Carteras por Tamaño-BM

ene-93 a dic-10: FFm

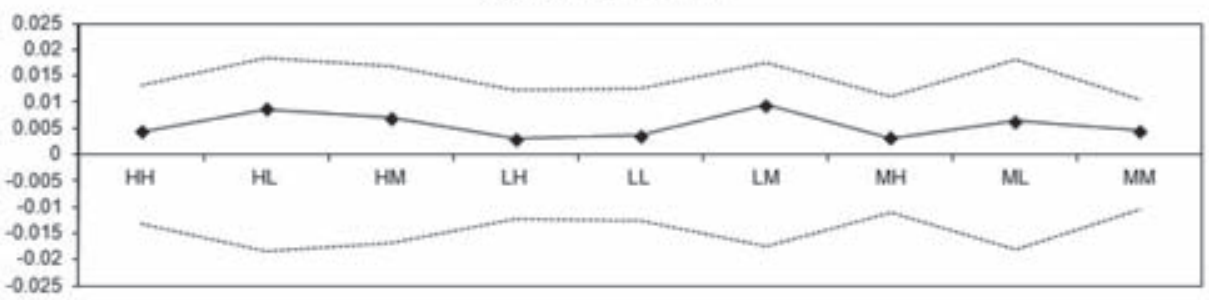

Error de estimación: 0.007415

ene-93 a dic-00: MEP

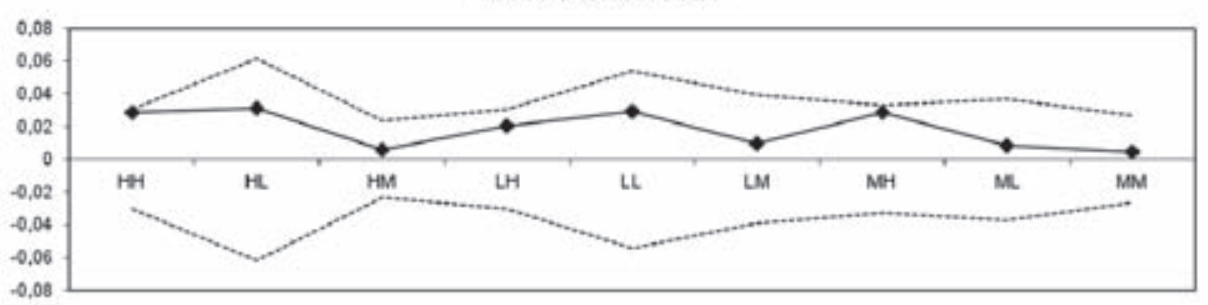

Error de estimación: 0.008764

ene-01 a dic-07: MCN

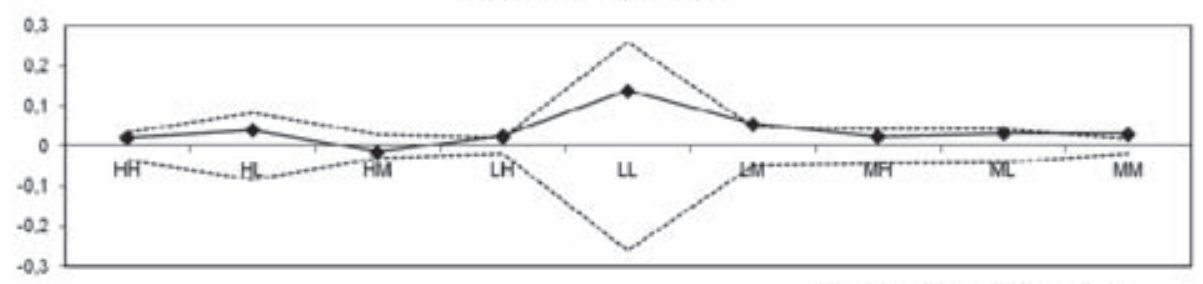

Error de estimación: 0.007823

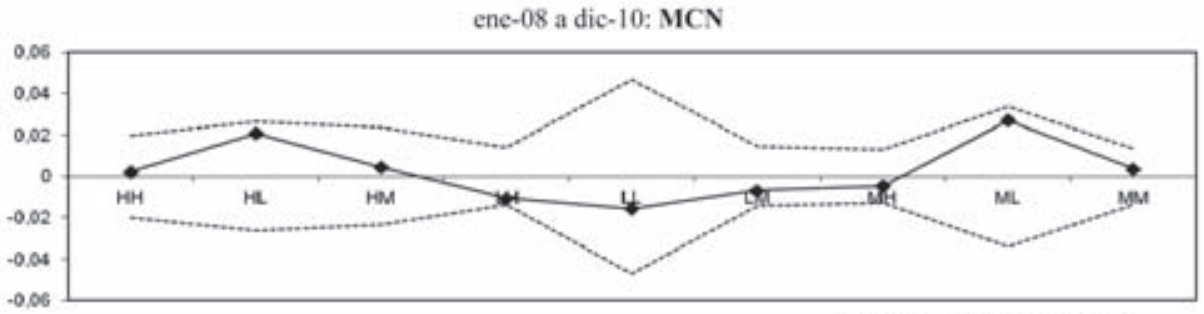

Error de estimación: 0.008146 
resultados no arrojan cambios sustanciales ${ }^{(13)}$ para ambas agrupaciones de activos: los signos de los coeficientes se mantienen en la misma línea, los errores de estimación son ligeramente más altos y en la mayoría de los casos los $R^{2}$ ajustados han descendido. La agrupación que se ha mostrado más sensible al cambio de metodología de estimación ha sido la de tamaño-BM y particularmente, para el modelo MCN. Para el primer procedimiento se registran niveles más altos de significatividad para los coeficientes estimados. Esto podría deberse, como era de esperar, a que el procedimiento rolling beta permite obtener estimaciones más ajustadas puesto que su carácter dinámico capta muchos matices que se pierden con la estimación de los parámetros solamente con un valor concreto. Estos resultados no han enmascarado en absoluto le elección de los mejores modelos propuestos por el otro procedimiento y que están dispuestos en la gráfica 2 .

\section{MODELOS DE VALORACIÓN Y METODOLOGÍA}

En este apartado facilitamos el detalle de los distintos modelos de valoración estimados en este artículo y la metodología de estimación y contraste aplicada.

\subsection{Modelos DE VALORACión}

En este trabajo comparamos la capacidad para explicar los precios de los activos financieros españoles de dos modelos de valoración competitivos: el modelo estructura productiva (MEP) y el modelo condiciones de negocio (MCN) que incorpora al mismo tiempo los dos factores, esto es, estructura productiva e innovación estratégica.

En primer lugar presentamos el modelo MEP, que considera el riesgo de mercado y el riesgo asociado a la estructura productiva, que mediremos a través de la serie FREP. La ecuación que lo define es:

$$
E\left(r_{j}\right)=\gamma_{o}+\gamma^{m} \beta_{j}^{m}+\gamma^{\text {frep }} \beta_{j}^{\text {frep }}
$$

donde $E\left(r_{j}\right)$ es el valor esperado de los excesos de rendimientos de un activo/cartera $j$ sobre el activo libre de riesgo del mercado doméstico; $\gamma^{m}$ es el valor esperado de los excesos de los rendimientos de la cartera de mercado respecto al activo libre de riesgo (prima de mercado) y $\gamma^{\text {frep }}$ el valor esperado de los rendimientos del factor FREP (prima estructura productiva); $\mathrm{y} \gamma^{m}$ es el riesgo beta de activo $j$ respecto a la cartera de mercado y $\beta_{j}^{\text {frep }}$ el riesgo beta de activo $j$ respecto al factor FREP. Nótese que el cumplimiento de este modelo y siguientes implica que $\gamma_{0}=0$. Para esta ecuación y la siguiente al in-

(13) El nuevo modelo regresado en serie temporal adopta la siguiente estructura:

$$
\Delta^{a} R B E_{j t}=\varphi_{j 0}+\mu_{j 1} \Delta^{a} K_{j t}+\psi_{j 2} \Delta^{a} L_{j t}+e_{j t}, \quad a=1,2,3,4 ; j=1, \ldots, N
$$

Los cambios más destacados solo afectan al modelo MCN y subperíodo pre-euro, donde el parámetro FREP pasa a ser no significativo para las carteras por sector y baja su nivel de significatividad pasando de un $1 \%$ a un $10 \%$ para las carteras por tamaño-BM. El parámetro FRIE (también para modelo MCN y subperíodo pre-euro) experimenta un cambio de signo: antes era positivo $(0,0000151)$ y no significativo, ahora es negativo $(-0,001089)$ y significativo al $1 \%$. Finalmente, para el modelo MCN y agrupación tamaño-BM se reducen los $R^{2}$ ajustados para el período completo (pasando de 0,19701 a 0,08715) y subperíodo pre-euro (pasando de 0,14052 a 0,06631). El detalle de estos resultados está a disposición de cualquier lector que desee estudiarlos con más profundidad. 
cluir $\gamma_{o}$ permite considerar una formulación del tipo Black (1972) con un rendimiento para el activo cero-beta igual al activo libre de riesgo más $\gamma_{0}$.

El segundo modelo es el modelo $M C N$ que integra los factores mercado, estructura productiva (FREP) e innovación estratégica medida a través de la serie FRIE, y se define por:

$$
E\left(r_{j}\right)=\gamma_{o}+\gamma^{m} \beta_{j}^{m}+\gamma^{\text {frep }} \beta_{j}^{\text {frep }}+\gamma^{\text {frie }} \beta_{j}^{\text {frie }}
$$

donde $\gamma^{\text {frep }} \mathrm{y} \gamma^{\text {frie }}$ son los valores esperados de los rendimientos del factor de riesgo asociado al factor FREP (prima asociada a la estructura productiva) y al factor FRIE (prima asociada a la capacidad de innovar) respectivamente; y $\beta_{j}^{\text {frep }}$ y $\beta_{j}^{\text {frie }}$ son los riesgos beta de activo j respecto a los factores FREP y FRIE respectivamente.

Tal y como se ha visto hasta el momento, hemos propuesto modelos multifactoriales donde se añade al factor de mercado dos nuevos factores (asociados a la estructura productiva y a la innovación estratégica). En los últimos años se ha apreciado una proliferación de trabajos que proponen nuevos factores y es imprescindible demostrar que estos nuevos factores ofrecen un poder explicativo más allá de aquellos factores adicionales más comúnmente utilizados, factores que han sido sometidos a numerosas pruebas de robustez: los factores tamaño, ratio book-to-market y momentum. Además, la relación existente con el momentum en beneficios es algo de esperar, dado que los factores asociados a la «estructura productiva» y a la «innovación estrategia» se estiman como un componente del cambio en el resultado bruto de explotación. Si bien es cierto que el efecto momentum en precios se ha debilitado considerablemente en el mercado español en los últimos años, no ha sucedido lo mismo con el efecto mometum en los beneficios (véase Forner, Sanabria y Marhuenda, 2009). Tomando estas consideraciones, también se estima en este trabajo el modelo de tres factores de Fama y French (1993) añadiendo el factor momentum (negociación) (que denotamos por FFm) para establecer más adelante una comparativa respecto al modelo que integra estos nuevos factores. El modelo FFm que proponemos viene definido por:

$$
E\left(r_{j}\right)=\gamma_{o}+\gamma^{m} \beta_{j}^{m}+\gamma^{s m b} \beta_{j}^{s m b}+\gamma^{h m l} \beta_{j}^{h m l}+\sum_{k} g^{m o m_{-} k} M O M_{-} k
$$

donde $\gamma^{s m b}$ y $\gamma^{h m l}$ son los valores esperados de los rendimientos del factor SMB (prima asociada al tamaño) y factor HML, (prima asociada al ratio book-to-market) respectivamente; $\beta_{j}^{s m b}$ y $\beta_{j}^{h m l}$ son los riesgo beta de activo j respecto a los factores SMB y HML respectivamente; y $g^{m o m \_k}$ es el coeficiente asociado al efecto (factor de negociación) momentum k-ésimo; MOM_k es la cartera efecto momentum k-ésima. Este modelo incluye como casos particulares: el modelo CAPM si aceptamos la hipótesis $\gamma^{\text {smb }}=0$, $\gamma^{h m l}=0, g^{m o m \_k}=0, \forall \mathrm{k}$.

\subsection{Aproximación eConométrica para el modelo estructura Productiva y Modelo CONDICIONES DE NEGOCIO}

En los preceptos teóricos que formulan los modelos asumimos que los primeros y segundos momentos de los rendimientos de los activos son constantes. Esta conjetura no se ajusta a la realidad, dado que el ambiente en todas las plazas financieras es bastante hostil y se genera nueva información que de forma inmediata se incorpora al precio de los activos financieros. Dicho lo cual, en este artículo asumiremos el cumplimiento 
condicional (y no estático o incondicional) de la metodología expuesta y desarrollaremos para su formulación marginal y posterior estimación el procedimiento escalado $^{(14)}$ propuesto en Cochrane (1996) con dos variables de estado: div y term. Siguiendo esta metodología los modelos $M E P$ y $M C N$, en su versión marginal, quedan expuestos a través de las siguientes relaciones matemáticas:

$$
\begin{gathered}
E\left(r_{j}\right)=\gamma_{0}+\gamma^{m} \beta_{j}^{m}+\gamma^{\text {frep }} \beta_{j}^{\text {frep }}+\gamma^{m \cdot d i v} \beta_{j}^{\text {m.div }}+\gamma^{\text {frep.div }} \beta_{j}^{\text {frep.div }}+\gamma^{\text {m.term }} \beta_{j}^{\text {m.term }}+ \\
\gamma^{\text {frep.term }} \beta_{j}^{\text {frep.term }}+\gamma^{\text {div }} \beta_{j}^{\text {div }}+\gamma^{\text {term }} \beta_{j}^{\text {term }} \\
E\left(r_{j}\right)=\gamma_{o}+\gamma^{m} \beta_{j}^{m}+\gamma^{\text {frep }} \beta_{j}^{\text {frep }}+\gamma^{\text {frie }} \beta_{j}^{\text {frie }}+\gamma^{\text {frddiv }} \beta_{j}^{\text {m.div }}+\gamma^{\text {frep.div }} \beta_{j}^{\text {frep.div }}+\gamma^{\text {frie.div }} \\
\beta_{j}^{\text {frie.div }}+\gamma^{\text {m.term }} \beta_{j}^{\text {m.term }}+\gamma^{\text {frepterm }} \beta_{j}^{\text {frep.term }}+\gamma^{\text {frie.term }} \beta_{j}^{\text {frie.term }}+\gamma^{\text {div }} \beta_{j}^{\text {div }}+\gamma^{\text {term }} \beta_{j}^{\text {term }}
\end{gathered}
$$

donde $E\left(r_{j}\right)$ es el valor esperado de los excesos de rendimientos de un activo/cartera $j$ sobre el activo libre de riesgo del mercado; $\gamma^{m}, \gamma^{\text {frep }}$ y $\gamma^{\text {frie }}$ son las primas de riesgo de mercado y asociadas a los factores de riesgo asociados a la estructura productiva, a la innovación estratégica, respectivamente; $\beta_{j}^{m}$, $\beta_{j}^{\text {frep }}$ y $\beta_{j}^{\text {frie }}$ son los riesgos beta de un activo/cartera $j$ respecto a las carteras de mercado y asociadas a los factores de riesgo asociado a la estructura productiva y a la innovación estratégica, respectivamente; $\gamma^{F \cdot I}$ y $\beta_{j}^{F \cdot I}, F=m$, frep, frie, $I=d i v$, term tienen la misma interpretación pero para los efectos cruzados de los factores de riesgo con las variables de estado retardadas un mes; y $\gamma^{I} \mathrm{y}$ $\beta_{j}^{I}, I=$ div, term son primas y riesgos beta asociados a la variación del ciclo económico recogida por las variables de estado retardadas un mes.

Presentamos los resultados de este artículo en base a una estimación condicional de los modelos $M E P$ [véase ecuación (6)] y $M C N$ [véase ecuación (7)] para las agrupaciones de carteras por sector y por tamaño-BM; la cuantificación y comparación de las primas económicas (premias) relativas a los riesgos asociados a la estructura productiva y a la innovación estratégica, y, en definitiva, una comparativa entre los modelos de valoración: $M E P, M C N, C A P M$ y FFm.

Estimamos estos modelos aplicando el procedimiento desarrollado en Fama y MacBeth (1973). Esta metodología ha sido aplicada en abundantes trabajos ${ }^{(15)}$, a nivel nacional e internacional, para estimar los modelos de valoración y analizar la estructura de sección cruzada de los rendimientos de los activos. Se desarrolla en dos fases que, al ser aplicado usando los datos de una ventana de observación que se desplaza mes a mes, permite obtener las series condicionales de los riesgos beta y primas al riesgo asociados a cada factor (véanse Ferson y Harvey, 1991, 1999). Esta metodología se caracteriza por ser flexible (en doble variante rolling beta) permitiendo así incorporar de forma progresiva los cambios que se van produciendo en el mercado. Cualidad que nos han hecho preferir esta metodología a la propuesta por Gibbons (1982), la cual estima conjuntamente ambos grupos de parámetros usando la muestra completa y el método GMM propuesto en Cochrane (1996). Como hemos expuesto en los primeros

(14) Partimos de la expresión en términos de la ecuación de valoración para llevar a cabo el proceso escalado de Cochrane (1996) en la valoración de los correspondientes modelos y se introduce la dinámica sobre los factores de descuento. Otra alternativa, es la propuesta en Dumas y Solnik (1995) y Jagannathan y Wang (1996), que consiste en introducir la dinámica directamente sobre las primas de riesgo.

(15) Véase, por ejemplo para el mercado de capitales español una colección de trabajos que utilizan esta misma metodología de estimación: Rubio (1988), Nieto (2002, 2004), Nieto y Rubio (2002), Miralles y Miralles (2003), Font y Grau (2007, 2009), Nieto y Rodríguez (2005) y Forner y Marhuenda (2006). 


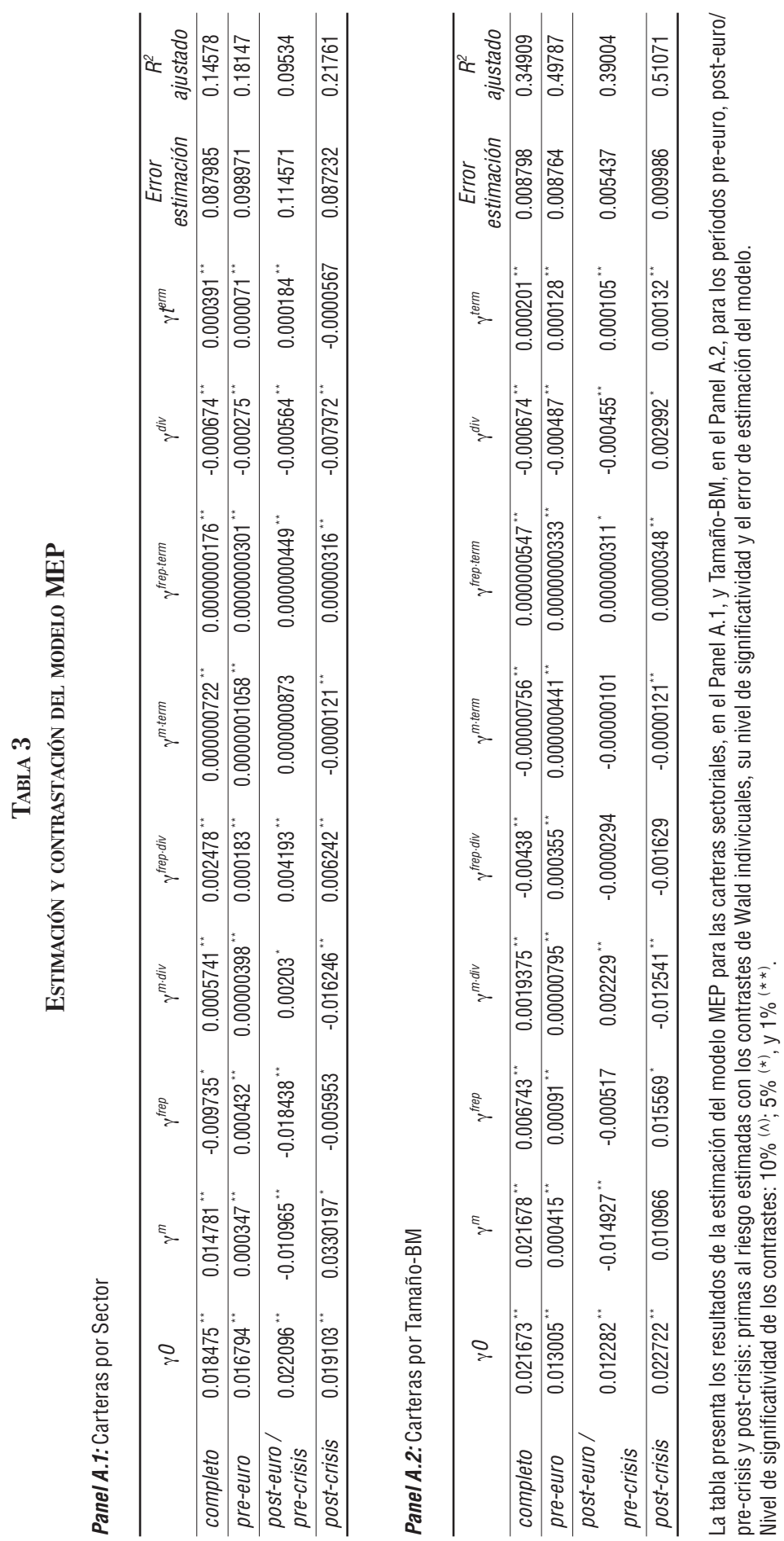


TABLA 4

ESTIMACIÓN Y CONTRASTACIÓN DEL MODELO MCN

Panel A.1: Carteras por Sector

\begin{tabular}{|c|c|c|c|c|c|c|c|c|}
\hline \multirow{4}{*}{ completo } & $\gamma_{0}$ & $\gamma^{m}$ & $\gamma^{\text {frep }}$ & $\gamma^{\text {frie }}$ & $\gamma^{m \cdot d i v}$ & $\gamma^{f f e p-d i v}$ & $\gamma^{\text {frie.div }}$ & $\gamma^{m \cdot t e r m}$ \\
\hline & 0.021746 & $-0.02973^{x+}$ & $-0.02181^{* *}$ & $-0.087248^{x x}$ & $0.0004871^{x}$ & $0.003766^{* *}$ & $0.004922^{\prime x}$ & $0.000001087^{* 2}$ \\
\hline & $\gamma^{\text {frep term }}$ & $\gamma^{\text {frie.term }}$ & $\gamma^{d i v}$ & $\gamma^{\text {term }}$ & Error estimación & $R^{2}$ ajustado & & \\
\hline & $0.000000064^{* *}$ & $-0.00000751^{* *}$ & $-0.00994^{* *}$ & $0.0000627^{* *}$ & 0.057445 & 0.28059 & & \\
\hline \multirow{4}{*}{ pre-euro } & $\gamma_{0}$ & $\gamma^{m}$ & $\gamma^{\text {frep }}$ & $\gamma^{\text {frie }}$ & $\gamma^{\text {m.div }}$ & $\gamma^{\text {frep div }}$ & $\gamma^{\text {frie.div }}$ & $\gamma^{m \cdot \text { term }}$ \\
\hline & $0.018719^{* *}$ & $0.000376^{* *}$ & $0.000367^{* *}$ & -0.00000713 & $0.0000103^{* *}$ & $0.000371^{* *}$ & $0.000809^{* *}$ & $0.000000158^{* 1}$ \\
\hline & $\gamma^{\text {frep-term }}$ & $\gamma^{\text {frie.term }}$ & $\gamma^{d i v}$ & $\gamma^{\text {term }}$ & Error estimación & $R^{2}$ ajustado & & \\
\hline & $0.0000000181^{* x}$ & $0.0000000059^{* *}$ & $-0.00028^{* *}$ & $0.0000539^{* *}$ & 0.543412 & 0.19411 & & \\
\hline \multirow{4}{*}{$\begin{array}{l}\text { post-euro } \\
\text { pre-crisis }\end{array}$} & $\gamma_{0}$ & $\gamma^{m}$ & $\gamma^{\text {frep }}$ & $\gamma^{\text {frie }}$ & $\gamma^{m \cdot d i v}$ & $\gamma^{\text {frep div }}$ & $\gamma^{\text {frie.div }}$ & $\gamma^{m \cdot t e r m}$ \\
\hline & $0.023201^{* *}$ & $-0.005937^{\wedge}$ & $-0.013839^{* *}$ & $-0.022652^{* *}$ & 0.000449 & $0.002983^{* *}$ & $0.003985^{* *}$ & 0.000000658 \\
\hline & $\gamma^{\text {frep-term }}$ & $\gamma^{\text {frie.term }}$ & $\gamma^{d i v}$ & $\gamma^{\text {term }}$ & Error estimación & $R^{2}$ ajustado & & \\
\hline & $0.000000449^{*}$ & $-0.000000606^{* *}$ & $-0.000675^{* x}$ & $0.000246^{* *}$ & 0.002449 & 0.33435 & & \\
\hline \multirow{4}{*}{ post-crisis } & $\gamma_{0}$ & $\gamma^{m}$ & $\gamma^{\text {frep }}$ & $\gamma^{\text {frie }}$ & $\gamma^{m \cdot d i v}$ & $\gamma^{\text {frep-div }}$ & $\gamma^{\text {frie.div }}$ & $\gamma^{m \cdot t e r m}$ \\
\hline & $0.018255^{\circ *}$ & $-0.043887^{*}$ & $-0.026256^{* *}$ & $-0.094087^{* *}$ & 0.000931 & $0.01297^{* *}$ & $0.020229^{* *}$ & $-0.0000185^{* *}$ \\
\hline & $\gamma^{\text {frep-term }}$ & $\gamma^{\text {frie.term }}$ & $\gamma^{d i v}$ & $\gamma^{\text {term }}$ & Error estimación & $R^{2}$ ajustado & & \\
\hline & $0.00000101^{* *}$ & $-0.00000327^{* *}$ & $-0.010884^{* *}$ & $0.00015^{*}$ & 0.001857 & 0.38663 & & \\
\hline
\end{tabular}

Panel A.2: Carteras por Tamaño-BM

\begin{tabular}{|c|c|c|c|c|c|c|c|c|}
\hline \multirow{4}{*}{ completo } & $\gamma_{0}$ & $\gamma^{m}$ & $\gamma^{\text {flep }}$ & $\gamma$ frie & $\gamma \mathrm{m} \cdot \mathrm{div}$ & $\gamma^{\text {fiep-div }}$ & $\gamma^{\text {fried-div }}$ & $\gamma^{\text {m.term }}$ \\
\hline & $0.019741^{* *}$ & $0.00973^{* \prime}$ & $0.0009455^{* *}$ & $-0.04588^{* *}$ & $-0.000944^{* *}$ & $-0.008541^{* *}$ & $0.005743^{* 1}$ & $0.00000709^{*}$ \\
\hline & $\gamma^{\text {frepterm }}$ & $\gamma^{\text {frie-term }}$ & $\gamma^{d i v}$ & $\gamma^{\text {term }}$ & Error estimación & $R^{2}$ ajustado & & \\
\hline & $0.000000471^{* *}$ & $-0.00000747^{*}$ & $-0.0005301^{* *}$ & $0.0002731^{* *}$ & 0.009778 & 0.19701 & & \\
\hline \multirow{4}{*}{ pre-euro } & $\gamma_{0}$ & $\gamma^{m}$ & $\gamma^{\text {ftep }}$ & $\gamma^{\text {frie }}$ & $\gamma^{m \cdot d i v}$ & $\gamma^{\text {frep-div }}$ & $\gamma^{\text {frie-div }}$ & $\gamma^{\text {m.term }}$ \\
\hline & $0.013148^{* *}$ & $0.000377^{*}$ & $0.000741^{* *}$ & 0.0000151 & $0.0000118^{* *}$ & $0.000387^{* 1}$ & $0.001422^{* *}$ & 0.000000517 \\
\hline & $\gamma^{\text {trepterm }}$ & $\gamma^{\text {frititerm }}$ & $\gamma^{d i v}$ & $\gamma^{\text {term }}$ & Error estimación & $R^{2}$ ajustado & & \\
\hline & $0.0000000249^{\prime \prime}$ & $0.00000000848^{* 1}$ & $-0.000453^{\prime \prime}$ & $0.000113^{* \prime}$ & 0.009206 & 0.14052 & & \\
\hline \multirow{4}{*}{$\begin{array}{l}\text { post-euro } \\
\text { pre-crisis }\end{array}$} & $\gamma_{0}$ & $\gamma^{m}$ & $\gamma^{\text {trep }}$ & $\gamma^{\text {frie }}$ & $\gamma^{m \cdot d i v}$ & $\gamma^{\text {frepdiv }}$ & $\gamma^{\text {frie-div }}$ & $\gamma^{\text {m.term }}$ \\
\hline & $0.01302^{\prime \prime}$ & $0.01207^{* 1}$ & $0.005714^{* 1}$ & -0.040688 " & $-0.001791^{* *}$ & $-0.001399^{\prime \prime}$ & $0.006344^{* *}$ & 0.00000124 \\
\hline & $\gamma^{\text {frep.term }}$ & $\gamma^{\text {frie term }}$ & $\gamma^{d i v}$ & $\gamma^{\text {term }}$ & Error estimación & $R^{2}$ ajustado & & \\
\hline & $0.000000904^{* *}$ & $-0.000000906^{* t}$ & $-0.000743^{*}$ & 0.000206 " & 0.007823 & 0.16093 & & \\
\hline \multirow{4}{*}{ post-crisis } & $\gamma_{0}$ & $\gamma^{m}$ & $\gamma^{\text {frep }}$ & $\gamma^{\text {frie }}$ & $\gamma^{\text {m.div }}$ & $\gamma^{\text {ffepdiv }}$ & $\gamma^{\text {frie.div }}$ & $\gamma^{\text {m.term }}$ \\
\hline & 0.028902 " & -0.023246 & $0.0006178^{*}$ & $-0.057747^{* *}$ & -0.00335 & $-0.017364^{* *}$ & $0.010364^{* \prime}$ & -0.00000502 \\
\hline & $\gamma^{\text {frepteterm }}$ & $\gamma^{\text {fria-term }}$ & $\gamma^{d i v}$ & $\gamma^{\text {term }}$ & Error estimación & $\mathrm{R}^{2}$ ajustado & & \\
\hline & $0.00000372^{* *}$ & $-0.00000668^{* *}$ & -0.001344 & $0.000224^{* *}$ & 0.008146 & 0.18418 & & \\
\hline
\end{tabular}

La tabla presenta los resultados de la estimación del modelo MCN para las carteras sectoriales, en el Panel A.1, y Tamaño-BM, en el Panel A.2, para los períodos pre-euro, post-euro/pre-crisis y post-crisis: primas al riesgo estimadas con los contrastes de Wald indivicuales, su nivel de significatividad y el error de estimación del modelo.

Nivel de significatividad de los contrastes: $10 \%{ }^{(\wedge)} ; 5 \%{ }^{(*)}$, y $1 \%{ }^{(* *)}$.

resultados descriptivos de la tabla 1 , las series de los rendimientos no presentan estructuras dinámicas ni en medias ni en varianzas, por tanto esta circunstancia nos ha hecho preferir este procedimiento (recordemos, Fama y MacBeth, 1973) a la metodología GARCH multivariante propuesta en De Santis y Gerard (1997) porque, aunque esta última metodología permite calcular las series condicionales de primas al riesgo (absolutos) de cada factor, asume una estructura dinámica GARCH sobre los excesos de rendimientos que no es adecuada para explicar nuestras series mensuales. 


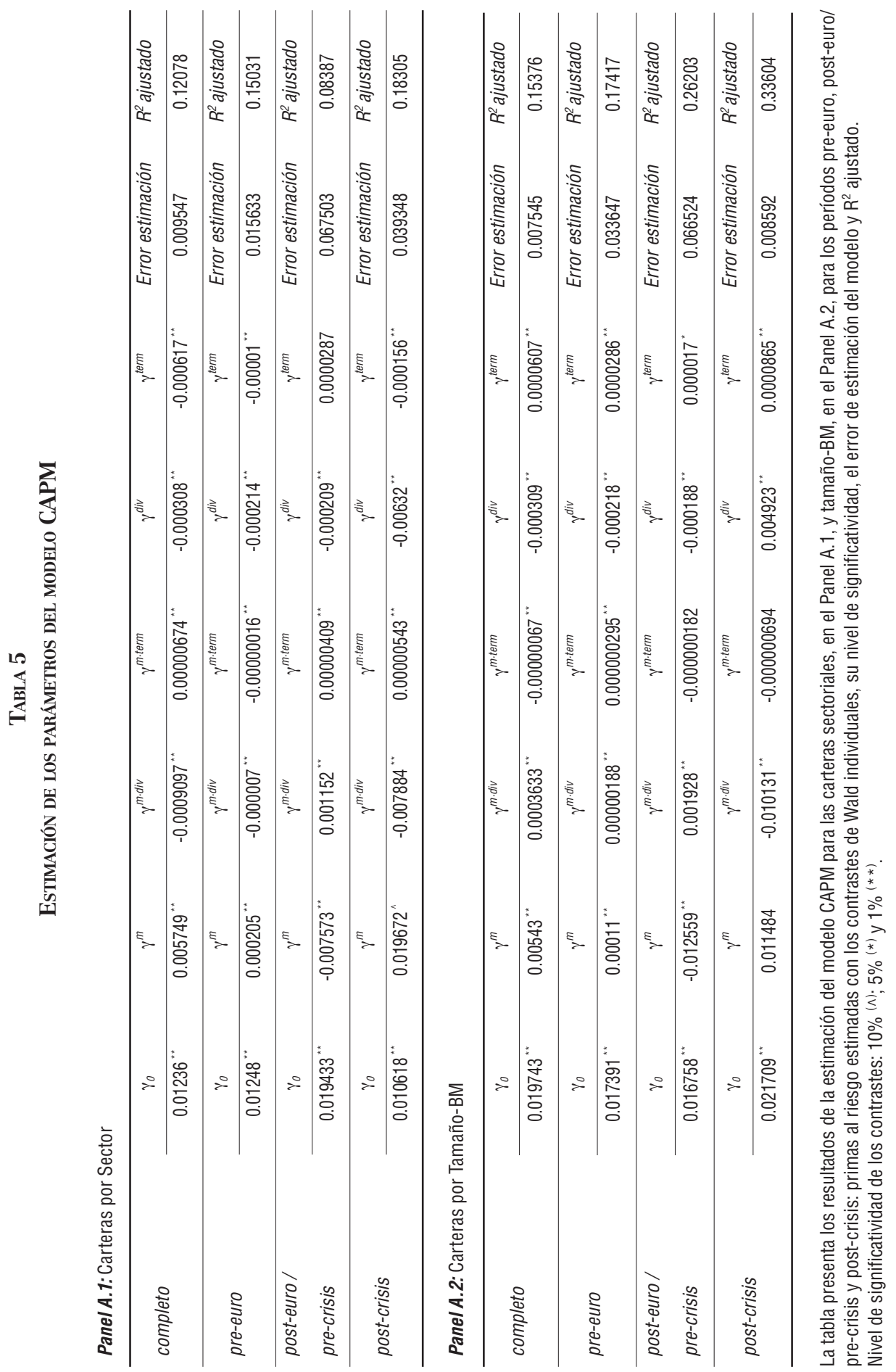


Como hemos indicado, el proceso de estimación se implementa en dos fases que procedemos a explicar. Primeramente estimamos para cada instante de tiempo $t$ $(t=1, \ldots, 216)$ por mínimos cuadrados ordinarios ${ }^{(16)}$ los riesgos beta de todos los factores (y de forma individual) regresando la serie de los excesos sobre el correspondiente factor $^{(17)}$, es decir, usando las 48 observaciones anteriores. En la siguiente fase estimamos, y de forma conjunta, aplicando el procedimiento SUR (con estimación simultánea de los coeficientes de las primas de riesgo y de la matriz de varianzas-covarianzas del modelo) las primas al riesgo para cada instante de tiempo $t$ regresando conjuntamente los excesos de rendimientos de las carteras de cada agrupación sobre los riesgos beta correspondientes (estimadas en la fase anterior) de las 48 observaciones anteriores. Tomando los resultados de la segunda fase calculamos el estimador de las primas para todo el periodo, se realizamos los contrastes individuales y conjuntos (de especificación) de los parámetros de cada modelo, y obtenemos las series de errores. Posteriormente calculamos el error de estimación de cada modelo a partir de la suma de la media del cuadrado de los errores (errores debidos a la sesgadez del estimador) más la varianza.

Del resultado de la estimación obtenemos en la primera fase las series condicionales de los riesgos beta de cada factor, y en la segunda fase las series condicionales de las primas al riesgo de cada factor. La prima económica (premia) asociada a cada factor de riesgo está estrechamente ligada a la sensibilidad de cada cartera a las distintas fuentes de riesgo y puede cuantificarse (véase, por ejemplo, De Santis, Gerard y Hillion, 2003) desagregando los excesos de los rendimientos totales estimados para cada cartera a partir del correspondiente modelo de valoración.

A continuación, y para analizar los impactos económicos asociados a la estructura productiva (FREP) descomponemos los excesos de los rendimientos totales estimados para cada cartera a partir del modelo MEP [véase ecuación (6)]. Para estudiar el efecto de la premia únicamente sobre el mercado, la aproximación econométrica que utilizamos, es:

$$
\gamma^{m} \beta_{j}^{m}+\gamma^{m \cdot d i v} \beta_{j}^{m \cdot d i v}+\gamma^{m \cdot t e r m} \beta_{j}^{m \cdot t e r m}
$$

De forma análoga pero considerando solamente el impacto de las premias sobre la estructura productiva y conjuntamente de ambos factores, esto es, mercado y estructura productiva, hemos desarrollado las siguientes ecuaciones:

$$
\gamma^{\text {frep }} \beta_{j}^{\text {frep }}+\gamma^{\text {frep } \cdot d i v} \beta_{j}^{\text {frep div }}+\gamma^{\text {frep } \cdot \text { term }} \beta_{j}^{\text {frep term }}
$$

(16) Existe otro procedimiento alternativo al utilizado en este trabajo: el método generalizado de los momentos (GMM). Esta metodología, en su estructura, no precisa asumir que los rendimientos sean normales. Cabe señalar que a pesar de rechazarse el test de J-B se pueden estimar los rendimientos con el procedimiento OLS (tal y como se ha venido observando el la literatura financiera) ya que la eficiencia del procedimiento GMM está intrínsecamente ligada a la elección de las variables (factores) Z's para medir las distancias de Hansen y Jagannathan (esto es, una medida de ajuste del modelo construida como la $\chi^{2}$ de Hansen y Singleton, 1982, con la matriz de ponderaciones óptima) y no al mero hecho de que los rendimientos no sean normales.

(17) Encontramos otras opciones que posibilitan reducir los efectos de la multicolinealidad en las regresiones de sección cruzada. Otros trabajos estiman conjuntamente las betas regresando la serie de los excesos sobre el modelo más completo con todos los factores. La ventaja es la reducción de la multicolinealidad pero el inconveniente es que en ese caso se estiman las «betas de cada factor en la parte no explicada por los restantes» y los modelos teóricos no hablan de esas betas. 


$$
\begin{gathered}
\gamma_{o}+\gamma^{m} \beta_{j}^{m}+\gamma^{\text {frep }} \beta_{j}^{\text {frep }}+\gamma^{\text {m.div }} \beta_{j}^{m \cdot d i v}+\gamma^{\text {frep } \cdot d i v} \beta_{j}^{\text {frep } \cdot \text { div }}+\gamma^{\text {frie.div }} \beta_{j}^{\text {frie.div }} \\
+\gamma^{m \cdot t e r m} \beta_{j}^{\text {m.term }}+\gamma^{\text {frep.term }} \beta_{j}^{\text {frep.term }}+\gamma^{\text {div }} \beta_{j}^{\text {div }}+\gamma^{\text {term }} \beta_{j}^{\text {term }}
\end{gathered}
$$

Igualmente, para el segundo modelo $M C N$, [véase ecuación (7)] lo descomponemos en las siguientes primas económicas: premia mercado, premia estructura productiva, premia innovación estratégica, premia conjunta estructura productiva e innovación estratégica y premia total, en las siguientes expresiones econométricas:

$$
\begin{aligned}
& \gamma^{m} \beta_{j}^{m}+\gamma^{m \cdot d i v} \beta_{j}^{m \cdot d i v}+\gamma^{m \cdot t e r m} \beta_{j}^{m \cdot t e r m} \\
& \gamma^{\text {frep }} \beta_{j}^{\text {frep }}+\gamma^{\text {frep div }} \beta_{j}^{\text {frep div }}+\gamma^{\text {frep.term }} \beta_{j}^{\text {m.term }} \\
& \gamma^{\text {frie }} \beta_{j}^{\text {frie }}+\gamma^{\text {frie div }} \beta_{j}^{\text {frie div }}+\gamma^{\text {frie.term }} \beta_{j}^{\text {frie } \cdot \text { term }} \\
& \gamma^{\text {frep }} \beta_{j}^{\text {frep }}+\gamma^{\text {frep } \cdot d i v} \beta_{j}^{\text {frep } \cdot d i v}+\gamma^{\text {frep.term }} \beta_{j}^{\text {m.term }}+\gamma^{\text {frie }} \beta_{j}^{\text {frie }}+\gamma^{\text {frie div }} \beta_{j}^{\text {frie.div }}+\gamma^{\text {frie.term }} \beta_{j}^{\text {frie.term }} \\
& \gamma_{o}+\gamma^{m} \beta_{j}^{m}+\gamma^{\text {frep }} \beta_{j}^{\text {frep }}+\gamma^{\text {frie }} \beta_{j}^{\text {frie }}+\gamma^{m \cdot d i v} \beta_{j}^{m \cdot d i v}+\gamma^{\text {frep } \cdot d i v} \beta_{j}^{\text {frep } \cdot d i v}+\gamma^{\text {frie } \cdot d i v} \beta_{j}^{\text {frie } \cdot d i v} \\
& +\gamma^{\text {m.term }} \beta_{j}^{\text {m.term }}+\gamma^{\text {frep.term }} \beta_{j}^{\text {frep.term }}+\gamma^{\text {frie.term }} \beta_{j}^{\text {frie.term }}+\gamma^{\text {div }} \beta_{j}^{\text {div }}+\gamma^{\text {term }} \beta_{j}^{\text {term }}
\end{aligned}
$$

Cada uno de sus elementos, y generalizable para los modelos $M E P$ y $M C N$, se analiza utilizando las series de riesgos beta y primas de riesgo condicionales obtenidas en la primera y segunda fase de la estimación por Fama y MacBeth (1973) para cada modelo. El valor medio y error estándar de las primas económicas se computan para los tres subperíodos regresando las series de primas al riesgo con una constante y aplicando la corrección por heterocedasticidad y autocorrelación de Newey y West (1987).

\section{RESULTADOS EMPÍRICOS}

Este apartado lo hemos reservado para presentar y estudiar los resultados más destacados del presente trabajo. En primer lugar, estudiamos la capacidad de los factores asociados a la estructura productiva e innovación estratégica para explicar los rendimientos de los activos financieros españoles en sección cruzada, estimando los modelos $M E P$ [véase ecuación (6)] y $M C N$ [véase ecuación (7)]. En segundo lugar, comparamos los dos modelos de valoración presentados, entre ellos y, con otros dos modelos. El primero solo integra el riesgo de mercado para ver si existe contribución diferencial sobre los mismos, es decir, el modelo CAPM $\left(\gamma^{\text {frep }}=0\right.$ y $\left.\gamma^{\text {frie }}=0\right)$. Y el segundo el modelo de Fama y French (1993) extendido con el factor momentum (negociación). A continuación, establecemos una comparativa para verificar que modelo explica mejor los rendimientos de los activos para el período completo y subperíodos considerados. Y finalizamos el estudio analizando las consecuencias en la valoración de la no consideración de los factores estructura productiva e innovación estratégica en nuestros modelos, dicho de otra forma, valorar el impacto económico de las premias. 


\section{TABLA 6}

ESTIMACIÓN Y CONTRASTE DEL MODELO FFM

Panel A.1: Carteras por Sector

\begin{tabular}{|c|c|c|c|c|c|c|c|c|c|}
\hline \multirow{4}{*}{ completo } & $\gamma_{0}$ & $\gamma^{m}$ & $\gamma^{s m b}$ & $\gamma^{h \mid h l}$ & $g^{\text {mom3 }}$ & $g^{\text {momb }}$ & $g^{\operatorname{mom} 9}$ & $g^{\text {mom12 }}$ & $\gamma^{\text {m.div }}$ \\
\hline & $0.037874^{* *}$ & $0.004578^{\circ}$ & $0.0368745^{\wedge}$ & $-0.02247^{* *}$ & $-0.187487^{* *}$ & $-0.099751^{* *}$ & $0.134781^{* *}$ & $-0.310874^{* *}$ & $-0.019745^{* *}$ \\
\hline & $\gamma^{\text {smb-div }}$ & $\gamma^{\text {hmldiviv }}$ & $\gamma^{\text {miterm }}$ & $\gamma^{\text {smb:term }}$ & $\gamma^{\text {hmlterm }}$ & $\gamma^{d i v}$ & $\gamma^{\text {temm }}$ & Error estimación & $R^{2}$ ajustado \\
\hline & $0.007157^{* *}$ & 0.00000074 & 0.000000207 & -0.0000019 & $-0.0000009^{* *}$ & $-0.000711^{* *}$ & $-0.000944^{* *}$ & 0.007415 & 0.210874 \\
\hline \multirow{4}{*}{ pre-euro } & $\gamma_{0}$ & $\gamma^{m}$ & $\gamma^{s m b}$ & $\gamma^{\text {hml }}$ & $g^{\text {mom3 }}$ & $g^{\text {momb }}$ & $g^{m o m 9}$ & $g^{\text {mom12 }}$ & $\gamma^{\text {m.div }}$ \\
\hline & $0.006891^{* *}$ & $0.006108^{\circ}$ & $0.006974^{\wedge}$ & $-0.000421^{*}$ & $-0.00583^{* \prime}$ & $-0.001457^{*}$ & $0.097616 *$ & $-0.406743^{\circ}$ & $-0.006782^{* *}$ \\
\hline & $\gamma^{\text {smb-div }}$ & $\gamma^{\text {hmldiv }}$ & $\gamma^{\text {m:term }}$ & $\gamma^{\text {smb:term }}$ & $\gamma^{\text {hmlterm }}$ & $\gamma^{d i v}$ & $\gamma^{\text {term }}$ & Error estimación & $R^{2}$ ajustado \\
\hline & $-0.000667^{\wedge}$ & $-0.007079^{* *}$ & $0.0006678^{\circ}$ & $-0.000076^{\wedge}$ & $0.010048^{* *}$ & $-0.006472^{*}$ & $-0.003471^{* *}$ & 0.010767 & 0.200236 \\
\hline \multirow{4}{*}{$\begin{array}{l}\text { post-euro } \\
\text { /pre-crisis }\end{array}$} & $\gamma_{0}$ & $\gamma^{m}$ & $\gamma^{s m b}$ & $\gamma^{\text {hml }}$ & $9^{\text {mom3 }}$ & $g^{\text {mom6 }}$ & $g^{\text {mom9 }}$ & $g^{\text {mom12 }}$ & $\gamma^{\text {m.div }}$ \\
\hline & $0.000551^{*}$ & $-0.0000884^{\wedge}$ & $-0.007638^{*}$ & $-0.06474^{\prime \prime}$ & $-0.107635 "$ & $-0.067899^{* *}$ & $0.036793^{\circ}$ & $-0.085731^{* *}$ & $0.006671^{* *}$ \\
\hline & $\gamma^{\text {smb.div }}$ & $\gamma^{\text {hml-div }}$ & $\gamma^{\text {m.term }}$ & $\gamma^{\text {smbteterm }}$ & $\gamma^{\text {hmlterm }}$ & $\gamma^{d i v}$ & $\gamma^{\text {temm }}$ & Error estimación & $R^{2}$ ajustado \\
\hline & $0.010875^{*}$ & $-0.010783^{* *}$ & $0.005417^{\circ}$ & $-0.002079^{\wedge}$ & $0.003238^{*}$ & $-0.011472^{*}$ & $-0.005997^{* *}$ & 0.095762 & 0.286472 \\
\hline \multirow{4}{*}{ post-crisis } & $\gamma_{0}$ & $\gamma^{m}$ & $\gamma^{s m b}$ & $\gamma^{\text {hml }}$ & $g^{\text {mom3 }}$ & $g^{\text {momb }}$ & $g^{\text {mom9 }}$ & $g^{\text {mom12 }}$ & $\gamma^{m \cdot d i v}$ \\
\hline & $0.005037^{* *}$ & 0.007587 & $0.040096^{\wedge}$ & $-0.003787^{* *}$ & $-0.086455^{*}$ & $-0.035874^{*}$ & $0.049751^{\circ}$ & $-0.157874^{* *}$ & $-0.035612^{* *}$ \\
\hline & $\gamma^{\text {smbldiv }}$ & $\gamma^{\text {hmldiv }}$ & $\gamma^{\text {m.term }}$ & $\gamma^{\text {smb-term }}$ & $\gamma^{\text {hmlterm }}$ & $\gamma^{\text {div }}$ & $\gamma^{\text {temm }}$ & Error estimación & $R^{2}$ ajustado \\
\hline & $0.010766^{*}$ & $-0.004489^{\prime \prime}$ & 0.000557 & $-0.006331^{\wedge}$ & $-0.000624^{*}$ & $-0.006481^{*}$ & $-0.014062^{*}$ & 0.047683 & 0.097616 \\
\hline
\end{tabular}

Panel A.2: Carteras por tamaño-BM

\begin{tabular}{|c|c|c|c|c|c|c|c|c|c|}
\hline \multirow{4}{*}{ completo } & $\gamma_{0}$ & $\gamma^{m}$ & $\gamma^{s m b}$ & $\gamma^{h m l}$ & $g^{\text {mom3 }}$ & $g^{\text {momb }}$ & $g^{\text {momm9 }}$ & $9^{\text {mom12 }}$ & $\gamma^{m \cdot d i v}$ \\
\hline & 0.009874 " & $0.006741^{\circ}$ & $-0.005794^{\wedge}$ & $0.003794^{1}$ & $-0.097451^{* \prime}$ & $-0.098125^{\prime \prime}$ & 0.094058 & $-0.110874^{* *}$ & -0.0014875 \\
\hline & $\gamma^{\text {smb-div }}$ & $\gamma^{h m l d d i v}$ & $\gamma^{m \text { term }}$ & $\gamma^{\text {smb tetem }}$ & $\gamma^{\text {hmllterm }}$ & $\gamma^{d i v}$ & $\gamma^{\text {term }}$ & Error estimación & $R^{2}$ ajustado \\
\hline & $-0.0010794 "$ & $0.0030085^{*}$ & $-0.0000039^{* *}$ & $0.0000091^{* *}$ & $0.00000207^{*}$ & -0.000708 & $-0.0000408^{* *}$ & 0.007415 & 0.387453 \\
\hline \multirow{4}{*}{ pre-euro } & $\gamma_{0}$ & $\gamma^{m}$ & $\gamma^{s m b}$ & $\gamma^{\text {hml }}$ & $g^{\text {mom3 }}$ & $g^{\text {mom } 6}$ & $g^{\text {momm9 }}$ & $g^{\text {mom12 }}$ & $\gamma^{m \cdot d i v}$ \\
\hline & $0.018745^{\circ}$ & -0.003549 & $-0.010032^{\wedge}$ & $-0.017956^{\wedge}$ & $-0.004711^{* \prime}$ & -0.008743 & $-0.147461^{\wedge}$ & $-0.097851^{* *}$ & 0.003711 \\
\hline & $\gamma^{\text {smb-div }}$ & $\gamma^{h m l d \cdot d i v}$ & $\gamma^{\text {m.term }}$ & $\gamma^{\text {smb-term }}$ & $\gamma^{\text {hmlterm }}$ & $\gamma^{\text {div }}$ & $\gamma^{\text {term }}$ & Error estimación & $R^{2}$ ajustado \\
\hline & $-0.003085^{\circ}$ & 0.000024 & $-0.000393^{\circ}$ & $0.004378^{\circ}$ & 0.000664 " & $-0.000551^{\circ}$ & $-0.001077^{* \prime}$ & 0.054653 & 0.168974 \\
\hline \multirow{4}{*}{$\begin{array}{l}\text { post-euro/ } \\
\text { pre-crisis }\end{array}$} & $\gamma_{0}$ & $\gamma^{m}$ & $\gamma^{s m b}$ & $\gamma^{h m l}$ & $g^{\text {mom3 }}$ & $g^{\text {momb }}$ & $g^{\text {mom } 9}$ & $g^{\text {momt2 }}$ & $\gamma^{m \cdot d i v}$ \\
\hline & $0.005574^{\circ}$ & $-0.010076^{*}$ & $0.000561^{\circ}$ & $0.000946^{*}$ & $-0.015221^{* \prime}$ & $-0.000554^{*}$ & 0.0065711 & $-0.003382^{* *}$ & $-0.007361^{*}$ \\
\hline & $\gamma^{\text {smbdiv }}$ & $\gamma^{\text {hmlldiv }}$ & $\gamma^{\text {miterm }}$ & $\gamma^{\text {smb:term }}$ & $\gamma^{\text {hmllterm }}$ & $\gamma^{\text {div }}$ & $\gamma^{\text {term }}$ & Error estimación & $R^{2}$ ajustado \\
\hline & $-0.004428^{\prime \prime}$ & -0.000037 & $0.005524^{* \prime}$ & 0.000702 & -0.008004 & $-0.000141^{\wedge}$ & $-0.000446{ }^{*}$ & 0.019736 & 0.110923 \\
\hline \multirow{4}{*}{ post-crisis } & $\gamma_{0}$ & $\gamma^{m}$ & $\gamma^{s m b}$ & $\gamma^{h m l}$ & $g^{\text {mom3 }}$ & $g^{\text {mom } 6}$ & $g^{\operatorname{mom} 9}$ & $g^{\text {mom12 }}$ & $\gamma^{m \cdot d i v}$ \\
\hline & 0.006326 " & $0.000964^{*}$ & 0.006993 & $0.020764^{*}$ & -0.000447 & $-0.007734^{\circ}$ & $-0.027622^{\wedge}$ & $-0.055271^{*}$ & $-0.001994^{*}$ \\
\hline & $\gamma^{\text {smbdodiv }}$ & $\gamma^{\text {hmlldiv }}$ & $\gamma^{\text {mterm }}$ & $\gamma^{\text {smbteterm }}$ & $\gamma^{\text {hmlleterm }}$ & $\gamma^{d i v}$ & $\gamma^{\text {term }}$ & Error estimación & $R^{2}$ ajustado \\
\hline & -0.000054 & $0.010447^{*}$ & $-0.004497^{* 1}$ & -0.004053 & $-0.000638^{* 1}$ & -0.000055 & $-0.006624^{* \prime}$ & 0.026435 & 0.139745 \\
\hline
\end{tabular}

La tabla presenta los resultados de la estimación del modelo FFm para las carteras sectoriales, en el Panel A.1, y tamaño-BM, en el Panel A.2, para los períodos pre-euro, post-euro/pre-crisis y post-crisis: primas al riesgo estimadas con los contrastes de Wald individuales, su nivel de significatividad, el error de estimación del modelo y su $\mathrm{R}^{2}$ ajustado.

Nivel de significatividad de los contrastes: $10 \%{ }^{(\wedge)} ; 5 \%{ }^{(*)}$ y $1 \%{ }^{(* \star)}$.

\subsection{LOS FACTORES ASOCIADOS A LA ESTRUCTURA PRODUCTIVA EN LA VALORACIÓN DE LOS ACTIVOS FINANCIEROS}

En este apartado analizamos los resultados estadísticos obtenidos en el proceso de estimación del modelo MEP [véase ecuación (6)]. Según el gráfico 1 y para las dos agrupaciones, sector y tamaño-BM, el modelo MEP suministra resultados bastante coherentes de los datos utilizados, es decir, se acepta la hipótesis de insesgadez de los errores para una significatividad del $10 \%$ a razón de que los errores estimados se 
mantienen dentro de la banda de confianza. A través del gráfico 2: paneles A y B, se desvela que el modelo MEP en la valoración, no resulta ser mejor modelo que el FFm para describir los rendimientos medios de los activos financieros considerando el período completo, dado que su error de estimación es superior para ambas agrupaciones de carteras. Únicamente para el primer subperíodo y agrupación tamaño-BM el modelo $M E P$ resulta ser el modelo que mejor describe los rendimientos de los activos.

La tabla 3 en los paneles A.1 y A.2, revela la significatividad (al 1\%) de la prima de riesgo estructura productiva a título individual, considerando también los efectos cruzados con las variables de estado para ambas agrupaciones, a excepción del período post-crisis para las carteras por sector y período post-euro/pre-crisis (y efecto cruzado con div) para las carteras por tamaño-BM. Las primas de riesgo vinculadas a la estructura productiva por subperíodos oscila entre el $-1.84 \%$ a $0.043 \%$ mensual respectivamente para la agrupación por sector y de $-0.051 \%$ a $1.55 \%$ mensual para la agrupación tamaño-BM. A su vez, destaca la inestabilidad del parámetro FREP (solamente para la agrupación por sector) ya que se registra un cambio de signo para subperíodo pre-euro pasando a ser positivo. Sería el único tramo donde las variaciones en la estructura productiva afecta positivamente a los rendimientos medios de los activos, posiblemente ocasionado por las medidas que en materia de convergencia europea se estaban acometiendo para recibir la moneda única.

Paralelamente, en la tabla 7: paneles A.1 y B.1 (sector y tamaño-BM, respectivamente) se aprecia el rechazo (al 1\%) la hipótesis conjunta de que los riesgos para las variables de estado sean iguales entre sí e iguales a cero, confirmándose así la relevancia de la postura de valoración condicional que asumimos en este artículo. En cuanto a los riesgos asociados al factor estructura productiva, decir que, también se rechaza (al $1 \%$ ) la hipótesis conjunta de que estos riesgos sean nulos.

Atendiendo a los resultados de la tabla 8, en términos generales, apreciamos que independientemente de en qué subperíodo y agrupación nos encontremos, las primas económicas no sufren cambios de signo. Particularmente, estos resultados establecen la relevancia del factor riesgo asociado a la estructura productiva en la valoración de los activos españoles que pasamos a explicar. Estas premias significativas (véase el Panel A de la tabla 8), implican que omitir el factor de riesgo asociado a la estructura productiva provocaría una sobrevaloración de los rendimientos de las carteras sectoriales Industria, Financiero y Tecnológico. Para el sector Industria destacar que en el subperíodo post-crisis de 2007, no solamente aumenta el nivel de significatividad (del $5 \%$ al $1 \%$ ) si no que el valor del coeficiente es bastante más elevado (de 2,12\% mensual); para el sector Tecnológico sucede algo similar ya que en el último subperíodo se registra el valor más alto manteniendo la significatividad (al 1\%) en todos los tramos (de 5.78\% mensual), en cambio, la cartera Financiera ha registrado un leve descenso subperíodo a subperíodo para un nivel de significatividad del 1\% (de $0.71 \%$ mensual). Para la agrupación por tamaño-BM (véase el panel B de la tabla 8) también encontramos primas económicas significativas (al 5\%) para los rendimientos de algunas carteras. Concretamente, los rendimientos de las carteras LM y HH han ido descendiendo en valor hasta el subperíodo post-crisis de 2007, con un peligro de sobrevaloración del $2,17 \%$ y $0.84 \%$, respectivamente. Respecto a la cartera $\mathrm{LH}$, se registra un ligero aumento significativo (al 5\%) hasta alcanzar una sobrevaloración del 4.76\% mensual.

En resumen, la inversión en capital y recursos humanos que las empresas llevan a cabo son factores influyentes para explicar las variaciones de los rendimientos de los 


\section{TABLA 7}

\section{CONTRASTES DE ESPECIFICACIÓN PARA LOS MODELOS MEP, MCN, CAPM Y FFM}

\begin{tabular}{|c|c|c|c|c|}
\hline \multicolumn{5}{|c|}{$\begin{array}{l}\text { Panel A: Contrastes de especificación de los modelos MEP, MCN, CAPM y FFm para Sector } \\
\text { Panel A.1: Modelo MEP }\end{array}$} \\
\hline \multirow{2}{*}{$H_{0}$} & \multicolumn{4}{|c|}{ Sector } \\
\hline & completo & pre-euro & post-euro/pre-crisis & post-crisis \\
\hline$\gamma^{\mathrm{m}}=\gamma^{\mathrm{m} \cdot \mathrm{div}}=\gamma^{\mathrm{m} \cdot \mathrm{term}}=\gamma^{\text {div }}=\gamma^{\text {term }}=0$ & $49.34187^{* *}$ & $46.85474^{* *}$ & $41.86412^{* *}$ & $52.45876^{* *}$ \\
\hline$\gamma^{\mathrm{m} \cdot \mathrm{div}}=\gamma^{\mathrm{m} \cdot \mathrm{term}}=0$ & $61.74587^{\star *}$ & $59.74587^{* *}$ & $60.24619^{* *}$ & $63.12864^{* *}$ \\
\hline$\gamma^{\text {frep }}=\gamma^{\text {frep-div }}=\gamma^{\text {frep-term }}=0$ & $29.48712^{* *}$ & $33.85674 *$ & $34.29001^{* *}$ & $39.78519^{* *}$ \\
\hline$\gamma^{\text {frep-div }}=\gamma^{\text {frep } \cdot \text { term }}=0$ & $32.85471^{* *}$ & $19.74521^{* *}$ & $28.01478^{* *}$ & $41.00578^{* *}$ \\
\hline$\gamma^{m}=\gamma^{\text {frep }}=\gamma^{\text {m.div }}=\gamma^{\text {frep-div }}=\gamma^{\text {m.term }}=\gamma^{\text {frep-term }}=\gamma^{\text {div }}=\gamma^{\text {term }}=0$ & $62.11093^{* *}$ & $48.74521^{* *}$ & $52.07781^{* *}$ & $75.92004^{* *}$ \\
\hline$\gamma^{\mathrm{div}}=\gamma^{\mathrm{term}}=0$ & $61.35056^{* *}$ & $60.04787^{* *}$ & $72.34902^{* *}$ & $76.41578^{* *}$ \\
\hline \multicolumn{5}{|l|}{ Panel A.2: Modelo MCN } \\
\hline \multirow[t]{2}{*}{ 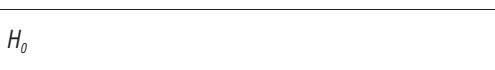 } & \multicolumn{4}{|c|}{ Sector } \\
\hline & completo & pre-euro & post-euro/pre-crisis & post-crisis \\
\hline$\gamma^{m}=\gamma^{m \cdot d i v}=\gamma^{m \text { term }}=\gamma^{\text {div }}=\gamma^{\text {temm }}=0$ & $38.57027^{* *}$ & $37.24951^{* *}$ & $41.87451^{\star *}$ & $61.76555^{* *}$ \\
\hline$\gamma^{m-d i v}=\gamma^{m \cdot \operatorname{term}}=0$ & $45.78541^{* *}$ & $39.07998^{* *}$ & $46.05745^{* *}$ & $49.24781^{* *}$ \\
\hline$\gamma^{\text {frep }}=\gamma^{\text {frepd-div }}=\gamma^{\text {frepterm }}=0$ & $81.44171^{* *}$ & $76.33571^{\star *}$ & $86.84157^{\star *}$ & $96.77149^{* *}$ \\
\hline$\gamma^{\text {frepdiv }}=\gamma^{\text {frep } \text { term }}=0$ & $101.9745^{* *}$ & $98.58047^{\star *}$ & $107.5319^{* *}$ & $106.8921^{* *}$ \\
\hline$\gamma^{\text {frci }}=\gamma^{\text {frididiv }}=\gamma^{\text {frititerm }}=0$ & $17.55419^{* *}$ & $20.07703^{* *}$ & $19.14874^{* *}$ & $22.07786^{* *}$ \\
\hline$\gamma^{\text {trididiv }}=\gamma^{\text {friciterm }}=0$ & $21.79451^{* *}$ & $21.00749^{* *}$ & $29.80477^{* *}$ & $29.99121^{* *}$ \\
\hline$\gamma^{\text {frep }}=\gamma^{\text {frei }}=\gamma^{\text {frep }- \text { div }}=\gamma^{\text {frodidiv }}=\gamma^{\text {frep } \text { term }}=\gamma^{\text {friciterm }}=0$ & $89.31157^{* *}$ & $82.47301^{* *}$ & $88.14806^{* *}$ & $84.72224^{* *}$ \\
\hline$\gamma^{m}=\gamma^{\text {frep }}=\gamma^{\text {frei }}=\gamma^{\text {m.div }}=\gamma^{\text {frep-div }}=\gamma^{\text {freidiv }}=\gamma^{m \cdot \text { term }}=\gamma^{\text {frep-term }}=\gamma^{\text {frciterm }}=0$ & $91.75317^{* *}$ & $79.27147^{* *}$ & $97.30827^{* *}$ & $100.0789^{* *}$ \\
\hline$\gamma^{d i v}=\gamma^{\text {tem }}=0$ & $96.74587^{* *}$ & $99.54774^{* *}$ & $106.2471^{* *}$ & $102.8543^{* *}$ \\
\hline
\end{tabular}

\begin{tabular}{|c|c|c|c|c|}
\hline \multicolumn{5}{|l|}{ Panel A.3: Modelo CAPM } \\
\hline \multirow{2}{*}{$H_{0}$} & \multicolumn{4}{|c|}{ Sector } \\
\hline & completo & pre-euro & post-euro/pre-crisis & post-crisis \\
\hline$\gamma^{m}=\gamma^{m \cdot d i v}=\gamma^{m \cdot t e r m}=\gamma^{d i v}=\gamma^{\text {term }}=0$ & $2814.129^{* *}$ & $2688.345^{* *}$ & $2875.056^{* *}$ & $2961.734^{* *}$ \\
\hline$\gamma^{m}=\gamma^{m \cdot d i v}=\gamma^{m \cdot t e r m}=0$ & $79.31615^{* *}$ & $81.41425^{* *}$ & $80.49741^{* *}$ & $87.45876^{* *}$ \\
\hline$\gamma^{m \cdot d i v}=\gamma^{m \cdot t e r m}=0$ & $99.57121^{* *}$ & $87.57127^{* *}$ & $104.8874^{* *}$ & $108.6478^{* *}$ \\
\hline$\gamma^{d i v}=\gamma^{\text {term }}=0$ & $50.63081^{* *}$ & $51.78414^{* *}$ & $67.84521^{* *}$ & $71.97845^{* *}$ \\
\hline \multicolumn{5}{|l|}{ Panel A.4: Modelo FFm } \\
\hline \multirow{2}{*}{$H_{0}$} & \multicolumn{4}{|c|}{ Sector } \\
\hline & completo & pre-euro & post-euro/pre-crisis & post-crisis \\
\hline $\begin{array}{l}\gamma_{0}=\gamma^{m}=\gamma^{\text {smb }}=\gamma^{\text {hml }}=g^{\text {mom3 }}=g^{\text {momb }}=g^{\text {momg }}=g^{\text {mom12 }}=\gamma^{m \cdot d \text { div }}= \\
\gamma^{\text {smb.div }}=\gamma^{\text {hml-div }}=\gamma^{\text {m.term }}=\gamma^{\text {smb.term }}=\gamma^{\text {mml-term }}=\gamma^{d \text { div }}=\gamma^{\text {term }}=0\end{array}$ & $16442.5^{* *}$ & $17648.6^{* *}$ & $9745.49^{* *}$ & $11733.1^{* *}$ \\
\hline$\gamma^{m}=\gamma^{m \cdot d i v}=\gamma^{m \cdot t e r m}=0$ & $59.7361^{* *}$ & $46.64871^{* *}$ & $29.8641^{\star *}$ & $32.98514^{* *}$ \\
\hline$\gamma^{s m b}=\gamma^{\text {smb.div }}=\gamma^{\text {smb.term }}=0$ & $364.741^{* *}$ & $267.5412^{* *}$ & $183.657^{\star *}$ & $201.626^{* *}$ \\
\hline$\gamma^{h m l}=\gamma^{h m l \cdot d i v}=\gamma^{h m l \cdot t e r m}=0$ & $822.154^{* *}$ & $1058.57^{* *}$ & $923.105^{* *}$ & $856.822^{* *}$ \\
\hline$g^{\text {mom3 }}=g^{\text {mom6 }}=g^{\text {mom9 }}=g^{\text {mom12 }}=0$ & $141.601^{* *}$ & $186.285^{* *}$ & $85.5676^{* *}$ & $99.2564 * *$ \\
\hline$\gamma^{d i v}=\gamma^{\text {term }}=0$ & $32.7461^{* *}$ & $29.9463^{* *}$ & $28.5477^{* *}$ & $41.8740^{* *}$ \\
\hline
\end{tabular}




\title{
TABLA 7 (CONT.)
}

\section{CONTRASTES dE ESPECIFICACión PARA LOS MODELOS MEP, MCN, CAPM Y FFM}

\author{
Panel B: Contrastes de especificación de los modelos MEP, MCN, CAPM y FFm para Tamaño-BM.
}

Panel B.1: Modelo MEP.

\begin{tabular}{|c|c|c|c|c|}
\hline \multirow{2}{*}{$H_{0}$} & \multicolumn{4}{|c|}{ Tamaño-BM } \\
\hline & completo & pre-euro & post-euro/pre-crisis & post-crisis \\
\hline$\gamma^{m}=\gamma^{m \cdot d \text { div }}=\gamma^{m \text {-term }}=\gamma^{\text {div }}=\gamma^{\text {term }}=0$ & $77.18596 *$ & $73.84531^{* *}$ & $73.72547^{* *}$ & $82.07386^{* *}$ \\
\hline$\gamma^{m \cdot d i v}=\gamma^{m \cdot t e r m}=0$ & $89.87457^{* *}$ & $86.42007^{* *}$ & $76.43799^{* *}$ & $88.39665^{* *}$ \\
\hline$\gamma^{\text {frep }}=\gamma^{\text {frep.div }}=\gamma^{\text {frep.term }}=0$ & $37.62557^{* *}$ & $39.85472^{\star *}$ & $38.80198^{\star \star}$ & $42.47577^{* *}$ \\
\hline$\gamma^{\text {frep-div }}=\gamma^{\text {frep-term }}=0$ & $54.87214^{* *}$ & $52.00739^{* *}$ & $56.87203^{\star *}$ & $59.74001^{* *}$ \\
\hline$\gamma^{m}=\gamma^{\text {frep }}=\gamma^{\text {m.div }}=\gamma^{\text {frep-div }}=\gamma^{\text {m.term }}=\gamma^{\text {frep-term }}=\gamma^{\text {div }}=\gamma^{\text {term }}=0$ & $87.15752^{* *}$ & $86.81047^{\star *}$ & $91.63418^{\star *}$ & $107.9452^{* *}$ \\
\hline$\gamma^{d i v}=\gamma^{\text {term }}=0$ & $50.67827^{* *}$ & $51.89745^{* *}$ & $61.97451^{\star *}$ & $64.57492^{* *}$ \\
\hline
\end{tabular}

\begin{tabular}{|c|c|c|c|c|}
\hline \multicolumn{5}{|l|}{ Panel B.2: Modelo MCN. } \\
\hline \multirow{2}{*}{$\ln _{1}$} & \multicolumn{4}{|c|}{ Tamaño-BM } \\
\hline & completo & pre-euro & post-euro/pre-crisis & post-crisis \\
\hline$\gamma^{m}=\gamma^{m \cdot d i v}=\gamma^{m \cdot \text { term }}=\gamma^{d i v}=\gamma^{\text {term }}=0$ & $21.57461^{* x}$ & $20.57221^{* *}$ & 18.86414 & $18.07664^{* *}$ \\
\hline$\gamma^{m \cdot d i v}=\gamma^{m \cdot t e r m}=0$ & $33.57874 * *$ & $19.87886 * *$ & $36.95573^{* *}$ & $41.97456 *$ \\
\hline$\gamma^{\text {frep }}=\gamma^{\text {frep-div }}=\gamma^{\text {frep } \text { term }}=0$ & $63.12518^{* *}$ & $60.93274 * *$ & $63.00471^{* *}$ & $70.00899^{* *}$ \\
\hline$\gamma^{\text {frep.div }}=\gamma^{\text {frep.term }}=0$ & $94.58875^{\star *}$ & 95.81320 ** & $101.3257^{* *}$ & $98.32874^{* *}$ \\
\hline$\gamma^{\text {frci }}=\gamma^{\text {frci-div }}=\gamma^{\text {frciterm }}=0$ & $78.51324^{* *}$ & $77.10112^{* *}$ & $97.23321^{* *}$ & $92.13504^{* *}$ \\
\hline$\gamma^{\text {frci-div }}=\gamma^{\text {friciterm }}=0$ & $84.35871^{* *}$ & $64.96544 * *$ & $86.87045^{* \star}$ & $89.04457^{* *}$ \\
\hline$\gamma^{\text {frep }}=\gamma^{\text {frci }}=\gamma^{\text {frep.div }}=\gamma^{\text {frcidiv }}=\gamma^{\text {frep } \text { term }}=\gamma^{\text {frciterm }}=0$ & $163.9815^{* *}$ & $147.2832^{* *}$ & $144.8974 * *$ & $167.3413^{* *}$ \\
\hline$\gamma^{m}=\gamma^{\text {frep }}=\gamma^{\text {frci }}=\gamma^{\text {m.div }}=\gamma^{\text {frep-div }}=\gamma^{\text {frcidivi }}=\gamma^{m \text {-term }}=\gamma^{\text {trep-term }}=\gamma^{\text {friciterm }}=0$ & $74.99844^{* *}$ & $85.01015^{* *}$ & $81.97452^{* *}$ & $84.2552^{* *}$ \\
\hline$\gamma^{d i v}=\gamma^{\text {term }}=0$ & $76.78547^{* *}$ & $81.32887^{* *}$ & $96.75540 * *$ & $102.6555^{* *}$ \\
\hline
\end{tabular}

\begin{tabular}{|c|c|c|c|c|}
\hline \multicolumn{5}{|l|}{ Panel B.3: Modelo CAPM. } \\
\hline \multirow{2}{*}{$H_{0}$} & \multicolumn{4}{|c|}{ Tamaño-BM } \\
\hline & completo & pre-euro & post-euro/pre-crisis & post-crisis \\
\hline$\gamma^{\mathrm{m}}=\gamma^{\mathrm{m} \cdot \mathrm{div}}=\gamma^{\mathrm{m} \cdot \mathrm{term}}=\gamma^{\text {div }}=\gamma^{\text {term }}=0$ & $1408.527^{* *}$ & $1706.998^{* *}$ & $1993.004^{\star *}$ & $1901.934^{* *}$ \\
\hline$\gamma^{\mathrm{m}}=\gamma^{\mathrm{m} \cdot \mathrm{div}}=\gamma^{\mathrm{m} \cdot \operatorname{term}}=0$ & $802.0998^{* *}$ & $812.7841^{* *}$ & $912.9514^{\star *}$ & $1055.944^{* *}$ \\
\hline$\gamma^{\mathrm{m} \cdot \mathrm{div}}=\gamma^{\mathrm{m} \cdot \operatorname{term}}=0$ & $796.6631^{* *}$ & $974.0112^{* *}$ & $905.0761^{* *}$ & $871.0703^{* *}$ \\
\hline$\gamma^{\mathrm{div}}=\gamma^{\text {term }}=0$ & $28.11528^{* *}$ & $39.74587^{* *}$ & $65.20056^{* *}$ & $86.57446^{* * *}$ \\
\hline
\end{tabular}

\begin{tabular}{|c|c|c|c|c|}
\hline \multicolumn{5}{|l|}{ Panel B.4: Modelo FFm. } \\
\hline \multirow{2}{*}{$H_{0}$} & \multicolumn{4}{|c|}{ Tamaño-BM } \\
\hline & completo & pre-euro & post-euro/pre-crisis & post-crisis \\
\hline 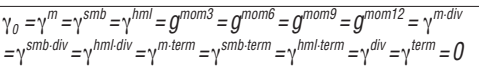 & $7486.75^{\star \star}$ & $11671.9^{\star \star}$ & $8964.66^{\star *}$ & $8147.41^{* *}$ \\
\hline$\gamma^{m}=\gamma^{m \cdot d i v}=\gamma^{m \cdot \text { term }}=0$ & $82.7419^{* \star}$ & $80.4612^{\star *}$ & $101.845^{\star \star}$ & $109.551^{\text {** }}$ \\
\hline$\gamma^{\text {smb }}=\gamma^{\text {smb.div }}=\gamma^{\text {smb.term }}=0$ & $435.684^{\star *}$ & $502.732^{\star *}$ & $954.554^{\star *}$ & $1012.05^{\star *}$ \\
\hline$\gamma^{h m l}=\gamma^{h m l \cdot d i v}=\gamma^{h m l \cdot t e r m}=0$ & $129.764^{\star *}$ & $195.963^{* *}$ & $108.787^{\star *}$ & $234.571^{* *}$ \\
\hline$g^{\text {mom3 }}=g^{\text {mom } 6}=g^{\text {mom } 9}=g^{\text {mom12 }}=0$ & $245.745^{\star *}$ & $276.668^{* *}$ & $305.974^{\star *}$ & $411.057^{\star *}$ \\
\hline$\gamma^{\text {div }}=\gamma^{\text {term }}=0$ & $19.7414^{\star *}$ & $18.9651^{* *}$ & $34.1038^{* *}$ & $56.0082^{* *}$ \\
\hline
\end{tabular}

La tabla presenta los resultados de los contrastes de Wald conjuntos, para las dos agrupaciones de carteras consideradas, de una selección de hipótesis de interés junto con su nivel de significatividad (para el período completo) y modelos MEP, MCN, CAPM y FFm, respectivamente.

Nivel de significatividad de los contrastes: $10 \%^{(\wedge)} ; 5 \%{ }^{(*)} ;$ y $1 \%{ }^{(* *)}$. 


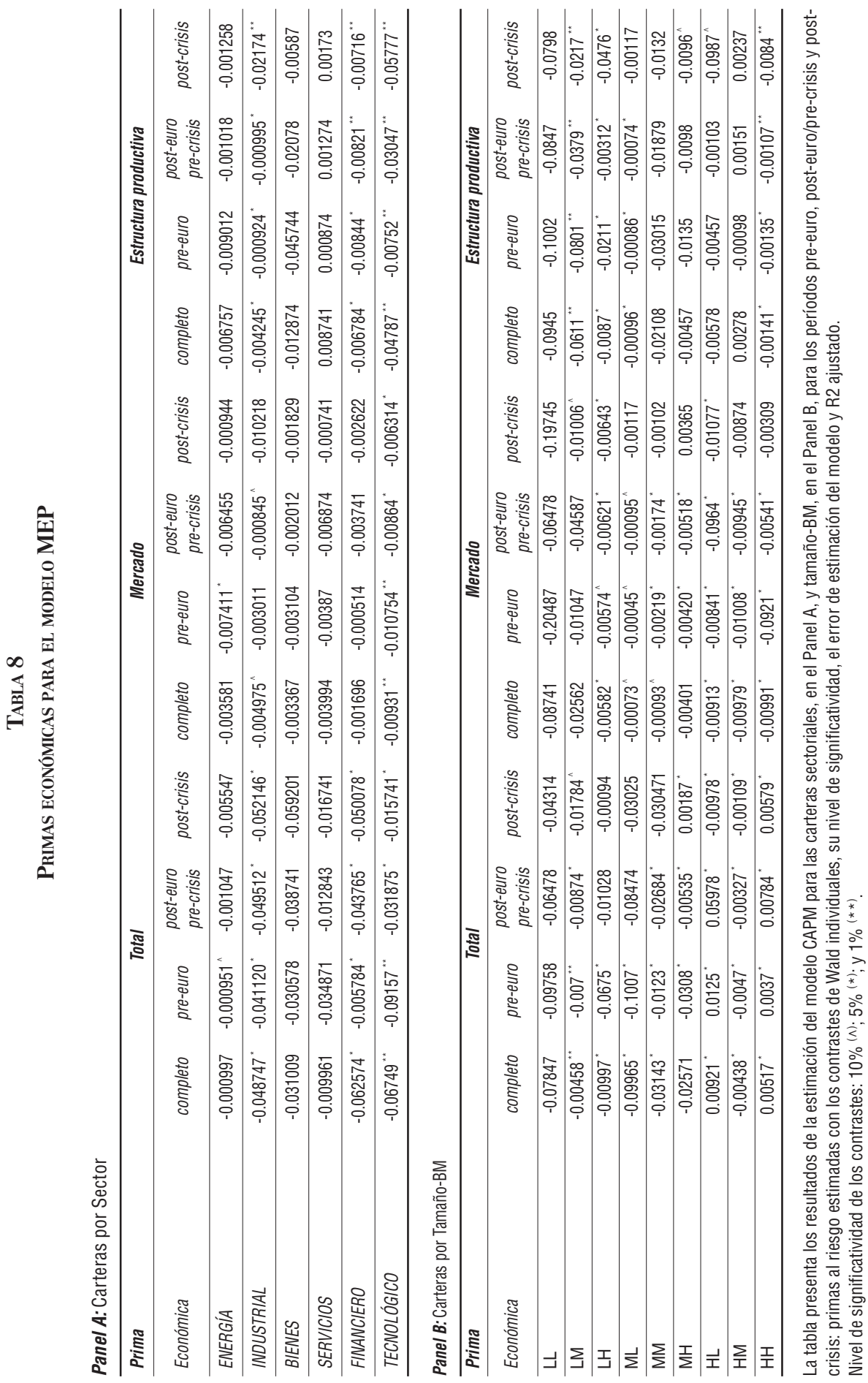


activos financieros en sección cruzada, medido a través del factor de riesgo estructura productiva (capital y trabajo). Pese a ser el modelo MEP un modelo adecuado para describir la formación del precio de los activos financieros, no lo es para todos los subperíodos y agrupaciones, es decir, sólo consigue situarse en primera fila para la agrupación tamaño-BM y para aquel subperíodo que abarca el inicio de la muestra hasta la adopción del Euro. El análisis del impacto de las premias pone de manifiesto que los rendimientos de gran parte de nuestras carteras estarían sobrevalorados si no se considerara el factor estructura productiva. En particular, en la agrupación por sector este efecto es mucho mayor, respecto al grupo tamaño-BM, dado que los valores del segundo al tercer subperíodo varían (incrementos) de forma muy notable.

\subsection{LOS FACTORES ASOCIADOS A LAS CONDICIONES DE NEGOCIO EN LA VALORACIÓN DE LOS ACTIVOS FINANCIEROS}

En este apartado analizamos los resultados estadísticos obtenidos en el proceso de estimación del modelo MCN [véase ecuación (7)]. Según el gráfico 1, el modelo $M C N$ también proporciona una representación sensata de todas las series y sobretodo, mucho mejor que la que se deriva del modelo MEP dado que la amplitud de su banda de confianza alcanza un rango de valores más estrecho tanto para la agrupación sector como tamaño-BM. De forma conjunta, los gráficos 1 y 2 indican que el modelo $M C N$, en general, es mejor modelo para explicar la evolución de los rendimientos de los activos financieros que el modelo MEP, pero inferior al modelo FFm, el cual muestra errores en la estimación bastante más bajos, considerando el período muestral completo. No obstante, por subperíodos y ambas agrupaciones, el modelo MCN es el mejor modelo para el segundo y tercer subperíodo, es decir, desde que se adopta la moneda única hasta diciembre de 2010.

Los contenidos de la tabla 4: paneles A.1 y A.2 nos indican que los factores de riesgo asociados a la estructura productiva y a la innovación estratégica son significativos (al 1\%) de forma conjunta (efecto individual y cruzado con las variables de estado) y de forma individual para las dos agrupaciones. Las primas de riesgo asociadas a la estructura productiva se mueven por subperíodos en los siguientes rangos: del $-2.62 \%$ a $0.036 \%$ mensual para la agrupación sectorial y del $0.0741 \%$ a $0.57 \%$ mensual para la agrupación tamaño-BM; las primas de riesgo asociadas a la innovación estratégica tienen un rango mensual entre el $-9.4 \%$ y el $-0.0007 \%$ para la agrupación sectorial y entre el $-5.77 \%$ y el $0.00015 \%$ mensual para la agrupación tamaño-BM. Al respecto encontramos que excepcionalmente para el factor innovación estratégica (FRIE) y ambas agrupaciones, no es significativo para el período pre-euro. Este análisis nos adelanta que los signos de los coeficientes FRIE son bastante estables en signo a través de los diferentes subperíodos; solamente hay un cambio de signo para la agrupación tamaño-BM en el subperíodo pre-euro pero resulta ser no significativo. Sin embargo, notemos que la incorporación al modelo MEP (factores de riesgo mercado y asociados a la estructura productiva) del factor de riesgo asociado a la innovación estratégica (modelo $M C N$ ) mejora los resultados de la estimación como podemos apreciar en el gráfico 1 y es responsable de los sesgos en los errores de estimación para ambas agrupaciones.

En cuanto a los resultados de estimación de la tabla 5, encontramos que las primas de mercado medidas por el modelo CAPM son significativas (al 5\%) en casi todos los casos. Estos resultados contrastan con los de otros autores, especialmente con Nieto 
y Rodríguez (2005), que a diferencia del presente, no obtienen primas significativas. Esto podría ser justificado por el procedimiento de estimación utilizado. En nuestro caso hemos regresado aplicando la técnica de doble rolling beta (mucho más flexible y adaptado a momentos de cambio) de manera que obtenemos una serie tanto para las betas como para las gamas. Los otros autores optan por estimar estas primas con un único valor para toda la muestra.

Tal y como apuntábamos en el apartado 3.1, es de vital importancia demostrar si los nuevos factores propuestos (estructura productiva e innovación estratégica) arrojan capacidad explicativa sobre los rendimientos de los activos, adicional respecto a los factores tradicionales de Fama y French (tamaño y ratio book-to-market) más factor momentum. Los resultados de estimación para el modelo FFm (véase tabla 6) nos proporcionan información muy relevante, que comparamos con los resultados de estimación para el modelo $M C N$ (véase tabla 4). Para la agrupación por sector (véase tabla 4: panel A.1) y períodos completo y subperíodos post-euro/pre-crisis y post-crisis, el error cometido por el modelo $M C N$, respecto al modelo FFm (véase tabla 6: panel A.1) es más reducido a la par que ofrece valores para el $\mathrm{R}^{2}$ ajustado más elevados (siendo el más destacable el del períodos post-crisis que pasa del 9.76\% al 38.66\%). En cuanto a la agrupación por tamaño-BM, el modelo FFm (véase tabla 6: panel A.2) comete un error de estimación más bajo con mayor $\mathrm{R}^{2}$ ajustado respecto al modelo $M C N$ (véase tabla 4: panel A.2). Estos resultados son matizables ya que por subperíodos el error cometido por el modelo $M C N$ es ligeramente menor a la par que los $\mathrm{R}^{2}$ ajustados son más elevados para los subperíodos post-euro/pre-crisis y post-crisis, respectivamente.

En consecuencia, estos datos nos conducen a pensar que los factores condiciones de negocio ofrecen información adicional respecto a los factores vinculados con el tamaño, ratio book-to-market y momentum. Estos hallazgos se cumplen con mayor fuerza para la agrupación por sector, siendo las carteras por tamaño-BM las que para la muestra completa se decantan ligeramente por el modelo de Fama y French ampliado con el factor momentum (negociación).

Nótese a través de la tabla 7: paneles A.2 y B.2, que la hipótesis conjunta de riesgos asociados a las variables de estado nulas, de acuerdo con la aproximación condicional que adoptamos en este trabajo, se rechaza al 1\% para ambas agrupaciones; y la hipótesis conjunta de que los riesgos asociados a la estructura productiva e innovación estratégica sean iguales entre sí e iguales a cero se rechaza (al 1\%) para las dos agrupaciones de carteras. Adicionalmente en el gráfico 1 se puede verificar que la hipótesis de insesgadez de los errores se acepta (al 10\%) para la agrupación sector y agrupación tamaño-BM, ya que los modelos se encuentran dentro de la banda de confianza.

Los resultados de la tabla 9 subrayan la importancia del factor de riesgo asociado a la estructura productiva en la valoración de los activos españoles, y confirman el escaso impacto económico del factor de riesgo asociado a la innovación estratégica, en especial para los dos primeros subperíodos, e indican que se produce una compensación de las primas económicas de ambos riesgos. En el Panel A de la tabla 9 identificamos premias significativas (al 5\%) para la agrupación sector, así es, una valoración basada en el modelo CAPM supondría nuevamente sobrevalorar entre un $-1.25 \%$ y un $-0.46 \%$, los rendimientos de las carteras del sector Industrial; sobrevalorar entre un $-2.15 \%$ y un $-1.064 \%$ para la cartera Bienes; sobrevalorar entre un $-1.957 \%$ y un $-0.847 \%$ para el sector Financiero; y finalmente, sobrevalorar la cartera Tecnológica entre un $-10.09 \%$ y un $-1.03 \%$, siendo esta última la cartera que ha experimentado el incremento más 


\section{TABLA 9}

\section{Primas eCONómicas PaRa El MODElo MCN}

Panel A: Carteras por Sector

\begin{tabular}{|c|c|c|c|c|c|c|c|c|c|c|c|c|}
\hline \multirow{2}{*}{$\begin{array}{l}\text { Prima } \\
\text { Económica }\end{array}$} & \multicolumn{6}{|c|}{ Total } & \multicolumn{6}{|c|}{ Mercado } \\
\hline & \multicolumn{2}{|c|}{ completo } & pre-euro & \multicolumn{2}{|c|}{$\begin{array}{l}\text { post-euro } \\
\text { pre-crisis }\end{array}$} & post-crisis & \multicolumn{2}{|l|}{ completo } & pre-euro & $\begin{array}{l}\text { post-euro } \\
\text { pre-crisis }\end{array}$ & \multicolumn{2}{|c|}{ post-crisis } \\
\hline ENERGÍA & \multicolumn{2}{|c|}{-0.008541} & -0.008451 & \multicolumn{2}{|c|}{-0.009655} & -0.007841 & \multicolumn{2}{|c|}{$-0.00795^{* *}$} & $-0.008171^{* *}$ & \multicolumn{2}{|c|}{$-0.007355^{* *}$} & $-0.006645^{* *}$ \\
\hline INDUSTRIAL & \multicolumn{2}{|c|}{-0.061524} & -0.059120 & \multicolumn{2}{|c|}{-0.056231} & -0.053836 & \multicolumn{2}{|c|}{-0.003854} & -0.002874 & \multicolumn{2}{|c|}{-0.003226} & -0.004182 \\
\hline BIENES & \multicolumn{2}{|c|}{-0.039675} & -0.038451 & \multicolumn{2}{|c|}{-0.033655} & -0.053765 & \multicolumn{2}{|c|}{-0.001974} & -0.002004 & \multicolumn{2}{|c|}{-0.001954} & -0.001915 \\
\hline SERVICIOS & \multicolumn{2}{|c|}{-0.011993} & -0.021746 & \multicolumn{2}{|c|}{-0.014843} & -0.008838 & \multicolumn{2}{|c|}{$-0.00567^{* *}$} & $-0.004157^{* *}$ & \multicolumn{2}{|c|}{$-0.0058855^{* *}$} & $-0.006845^{* 1}$ \\
\hline FINANCIERO & & 0.061824 & -0.041613 & \multicolumn{2}{|c|}{-0.040465} & -0.044764 & \multicolumn{2}{|c|}{-0.004184} & -0.003874 & \multicolumn{2}{|c|}{-0.003068} & -0.002916 \\
\hline TECNOLÓGICO & & 0.088227 & -0.087451 & \multicolumn{2}{|c|}{-0.030255} & -0.008765 & \multicolumn{2}{|c|}{$-0.00998^{\circ}$} & -0.010754 & -0.0090 & & $-0.007425^{*}$ \\
\hline Prima & & Estructura & productiva & & & Innovación & estratégica & & & Condicione & s Negocio & \\
\hline Económica & completo & pre-euro & $\begin{array}{l}\text { post-euro } \\
\text { pre-crisis }\end{array}$ & post-crisis & completo & pre-euro & $\begin{array}{l}\text { post-euro } \\
\text { pre-crisis }\end{array}$ & post-crisis & completo & pre-euro & $\begin{array}{l}\text { post-euro } \\
\text { pre-crisis }\end{array}$ & post-crisis \\
\hline ENERGÍA & 0.005487 & 0.007841 & 0.002341 & 0.00098 & $-0.01587^{\wedge}$ & -0.01978 & -0.02093 & $-0.02667^{*}$ & -0.01897 & -0.01010 & -0.01450 & -0.02211 \\
\hline INDUSTRIAL & -0.006164 & $-0.004574^{\wedge}$ & $-0.006091^{*}$ & $-0.01247^{*}$ & -0.05147 & -0.05864 & -0.05332 & $-0.0505^{*}$ & -0.05854 & -0.07457 & -0.07161 & $-0.06077^{*}$ \\
\hline BIENES & $-0.030971^{1}$ & $-0.021457^{*}$ & $-0.01742^{*}$ & $-0.01064^{*}$ & -0.09646 & -0.10845 & -0.06081 & -0.00982 & -0.08976 & -0.07154 & -0.07543 & -0.09210 \\
\hline SERVICIOS & -0.001087 & -0.001741 & -0.001125 & -0.00087 & -0.04154 & -0.03078 & -0.03171 & -0.04074 & -0.00962 & -0.01142 & -0.00911 & -0.00864 \\
\hline FINANCIERO & $-0.01173^{* \prime}$ & $-0.01027^{*}$ & $-0.00915^{* *}$ & $-0.00847^{*}$ & -0.03784 & -0.05945 & -0.05752 & -0.04951 & -0.01925 & -0.01404 & -0.01483 & -0.01678 \\
\hline TECNOLÓGICO & $-0.03754 "$ & $-0.00876 *$ & $-0.01957^{* *}$ & $-0.10087^{*}$ & -0.09747 & -0.04874 & -0.04169 & -0.00887 & -0.04567 & -0.03325 & -0.03825 & $-0.08408^{\wedge}$ \\
\hline
\end{tabular}

Panel B: Carteras por Tamaño-BM

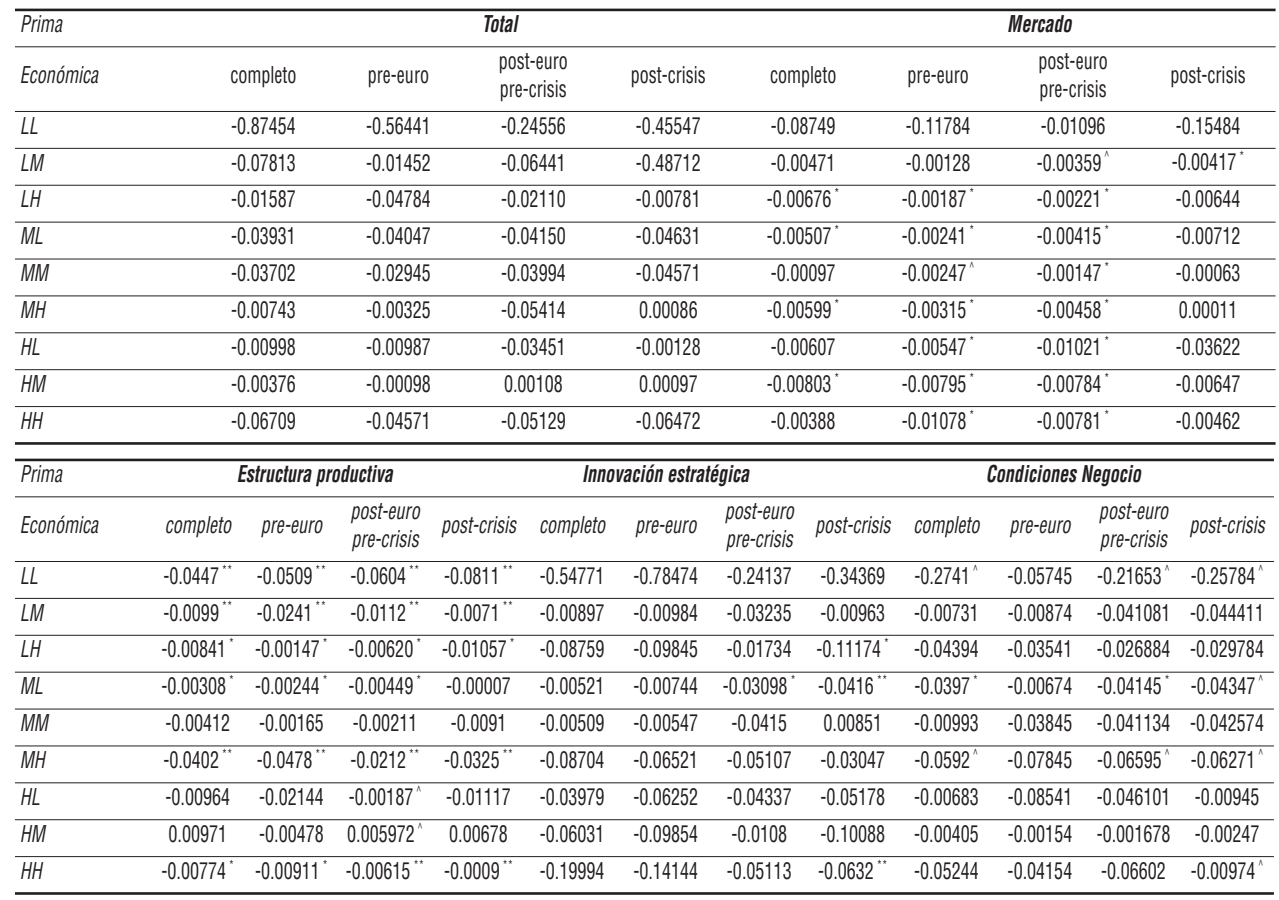

En la tabla se facilitan los estadísticos correspondientes a los resultados de las ecuaciones econométricas de (11) a (15) del modelo MCNy el contraste de Wald con su nivel de significatividad. Separamos en paneles el estudio para las dos agrupaciones considerando el período completo y los tres subperíodos en que se fracciona la muestra.

Nivel de significatividad de los contrastes: $10 \%{ }^{(\wedge)} ; 5 \%^{(*)}$ y $1 \%{ }^{(* *)}$. 
acusado una vez instalada la crisis de 2007 (tercer subperíodo). En el panel B de la tabla 9 se observan también primas económicas significativas (al 5\%), efectivamente, una valoración que considera únicamente el riesgo de mercado supondría sobrevalorar gran parte de los rendimientos de las carteras de la agrupación tamaño-BM. En todos los casos los rendimientos de las carteras están mensualmente sobrevaloradas, a saber: la cartera LL entre un $-8.11 \%$ y un $-5.09 \%$; la cartera LM entre un $-2.41 \%$ y un $-0.71 \%$; la cartera LH entre un $-1.06 \%$ y un $-0.147 \%$; la cartera MH entre un $-4.78 \%$ y un $-2.12 \%$; y para acabar, la cartera $\mathrm{HH}$ entre un $-0.91 \%$ y un $-0.09 \%$, siendo esta última cartera, HH, la que arroja el cambio más extremo al pasar de estar sobrevalorada del $-0.91 \%$ para el primer subperíodo a una sobrevaloración del $-0.009 \%$ una vez llegada la crisis de 2007, es más, el nivel de significatividad se eleva (del 5\% al 1\%).

Profundizando en los estadísticos de la tabla 9, analizamos ahora las consecuencias de una valoración exclusiva con el modelo CAPM que tampoco considerara el otro factor de riesgo objeto de nuestro estudio, la innovación estratégica. En general, y como se ha dicho, el impacto del factor de riesgo innovación estratégica tiene una contribución bastante marginal, es decir, hay pocos impactos económicos significativos. La tabla 9: Panel A, muestra estos resultados y nos revelan que solamente están sobrevaloradas los rendimientos de las carteras Energía e Industrial, para el subperíodo post-crisis con un $-2.67 \%$ mensual y $-5.1 \%$ mensual, respectivamente; en el Panel B observamos sobrevaloradas los rendimientos de las carteras LH, ML y HH, para el período postcrisis también y para unos valores de $-11.17 \%,-4.16 \%$ y $-6.32 \%$, respectivamente. $\mathrm{Si}$ bien la innovación estratégica viene explicada por aquellos factores no contenidos en la estructura productiva de la empresa, el acusado signo negativo de sus premias nos anticipa que los cambios en los resultados empresariales provocan un impacto de sobrevaloración (en nuestro caso muy escaso) en los rendimientos esperados.

El estudio conjunto de los dos factores de riesgo, esto es condiciones de negocio, también nos ofrece escasos valores significativos. Se registra sobrevalorada con un $-6.1 \%$ la cartera Industrial, solamente para el tercer subperíodo al 5\% de significatividad. En cambio, para la agrupación tamaño-BM se encuentran sobrevaloradas, pero al $10 \%$, los rendimientos de las carteras LL, ML, MH y HH.

Resumiendo, los resultados obtenidos con la estimación del modelo MCN revelan una mayor capacidad explicativa respecto al modelo MEP, dado el factor riesgo innovación estratégica que añade el primero respecto al segundo (aunque su relevancia no sea muy notable). Ulteriores resultados nos indican que la llegada del Euro ha provocado que los impactos en la sobrevaloración de la mayoría de los rendimientos de las carteras (y ambas agrupaciones), se hayan incrementado. Se observa este mismo efecto con una graduación mucho mayor una vez comenzado en período que registra el inicio de la crisis de 2007. Con estos resultados el mercado advierte que una gestión óptima en las inversiones que las empresas efectúen en sus estructuras productivas a través de la adquisición de bienes del inmovilizado, a la par que favorecer una adecuada fuerza productiva mediante el factor trabajo, es crucial y cada vez más relevante. Encontrar un adecuado equilibro entre estos dos factores constituye un parámetro relevante en materia de valoración y que el mercado cada vez exige en mayor medida. Con la llegada del Euro, nuestro mercado experimenta una apertura mucho mayor que la expone a una mayor competitividad y por tanto una mayor exigencia en la gestión de sus estructuras productivas. Estos efectos se acrecientan con la llegada de la crisis (dificultad para conseguir subvenciones y créditos a la inversión, políticas económicas 
restrictivas, caída de la producción por la baja demanda, etc.), dificultando todavía mucho más esta ardua tarea. Efectivamente, una valoración basada exclusivamente con el modelo CAPM implicaría sobrevalorar los rendimientos de muchas de las carteras, principalmente por la influencia del factor asociado a la estructura productiva, por tanto, para nuestro mercado los factores que podrían explicar la innovación estratégica no son factores tan influyentes, para explicar los rendimientos de los títulos cotizados en la bolsa española.

\section{CONCLUSIONES}

En este artículo proponemos dos objetivos fundamentales: cuantificar la contribución de las primas al riesgo asociadas a los factores estructura productiva e innovación estratégica, para explicar los rendimientos en sección cruzada de los activos cotizados en el mercado de capitales español. Separamos la muestra completa que va desde enero de 1993 a diciembre de 2010 en tres subperíodos que consideran los hechos políticos y económicos más relevantes (adopción del euro y la crisis financiera internacional). Seguidamente analizamos el impacto de las primas económicas (premias) en una valoración exclusivamente basada en un modelo que solo integra el riesgo de mercado.

El estudio de las implicaciones económicas que se derivan de la omisión de estos factores ha acaparado escasa atención por parte de la literatura tradicional, es más, pocos son los estudios que hacen una diagnosis exhaustiva utilizando factores asociados a la capacidad de innovar de las empresas, y prácticamente son inexistentes los que incorporan modelos de valoración.

Siguiendo esta línea de trabajo, con este artículo aportamos evidencia empírica sobre la relación, estadísticamente significativa, existente entre las condiciones de negocio de la empresa y los rendimientos de los activos financieros, siendo la influencia del factor estructura productiva mucho más relevante que el factor capacidad de innovar. Los resultados obtenidos se pueden resumir en los siguientes apartados:

- Los riesgos por estructura productiva e innovación estratégica son relevantes en el proceso de formación del precio de los activos financieros españoles. Efectivamente, a través del modelo condiciones de negocio $(M C N)$ (más completo que el modelo estructura productiva: $M E P$ ) observamos que las primas al riesgo asociadas a las condiciones de negocio son individualmente significativas (al 1\%) y los contrastes de especificación rechazan, para un nivel de significatividad del 1\%, que estas primas sean iguales entre sí e iguales a cero.

- El modelo condiciones de negocio (MCN) es el modelo que mejor describe los rendimientos de activos españoles en sección cruzada a partir de la adopción del Euro hasta el final de la muestra. Aunque para el período completo el mejor modelo es el modelo de Fama y French (1993) extendido con el factor momentum (negociación) $(F F m)$, al subdividir la muestra en tres subperíodos, los resultados cambian, parcialmente, a favor del modelo MCN. Esto se aprecia en sus errores de estimación más bajos en ambas agrupaciones, aunque no para todos los subperíodos. Para las carteras sectoriales resulta ser el mejor modelo pero solo para el último subperíodo (post-crisis de 2007). Sucede lo mismo en las carteras por tamaño-BM, ya que tras la adopción del Euro y la llegada de la crisis mundial registrada a mediados 
del 2007, los errores de estimación son más reducidos respecto al resto de modelos: MEP y FFm. En consecuencia, el hecho de que el modelo MCN para algunos subperíodos sea superior al modelo FFm, nos anticipa que los factores asociados a las condiciones de negocio tienen capacidad explicativa por encima de los «clásicos» factores de Fama y French (1993) más factor momentum.

- Una valoración basada en un modelo que solo considera el riesgo de mercado supone, para los dos últimos superíodos por el impacto económico de los factores estructura productiva e innovación estratégica, una sobrevaloración de los rendimientos de un número considerable de carteras en ambas agrupaciones. Esta relevancia se agudiza más a medida que pasamos de un subperíodo a otro, es decir, existe peligro de sobrevaloración en el primer subperíodo, experimentando un ligero ascenso tras la adopción del Euro, el cual se incremente notablemente cuando se instala la crisis de 2007 en los mercados de capitales.

A la luz de todas estas evidencias empíricas, creemos que el presente trabajo aporta información relevante sobre un grupo de factores, que en diferente medida, contribuyen significativamente a la formación de los precios de cotización de los títulos valores españoles. Estos resultados podrían estar estrechamente ligados tanto a la extensión espacial de la muestra, como al mercado donde se ha desarrollado. Pensamos que las características intrínsecas de los sectores que conforman cada país, podría arrojar resultados bastante diferenciadores a la par que interesantes como posible futuro objeto de estudio. Adicionalmente, el factor innovación estratégica tiene poca relevancia en la formación de los precios. Por tanto, como futura línea de trabajo y de mejora del presente artículo, podría consistir en realizar este estudio considerando adicionalmente otros mercados europeos y hacer una comparativa entre ellos y poder apreciar así, si la escasa significatividad del factor innovación estratégica en España es una característica propia de nuestro mercado o generalizable a otros mercados.

\section{REFERENCIAS BIBLIOGRÁFICAS}

BAnz, R. 1981. The relationship between return and market value common stocks. Journal of Financial Economics 9: 33-18.

BLACK, F. 1972. Capital market equilibrium with restricted borrowing. Journal of Business 45: 444-455.

Cochrane, J. H. 1996. A cross-sectional test of an investment based asset pricing models. Journal of Political Economy 104: 572-621.

ConRAD, J.; GUltekin, M.N., y KAUl G. 1991. Asymmetric predictability of condicional variances. The Review of Financial Studies 4: 597-622.

Debondt, W., y Thaler, R. 1985. Does the stock market overreact. The Journal of Finance 40(3): 793-805.

De Santis, G., y Gerard, B. 1997. International asset pricing and portfolio diversification with time-varying risk. The Journal of Finance 52: 1.881-1.912.

De Santis, G.; GÉRARD, B., y Hillion, P. 2003. The relevance of currency risk in the EMU. Journal of Economics and Business 55: 427-462.

Dumas, B., y Solnik, B. 1995. The world price of foreign exchange risk. The Journal of Finance 50 (2): 445-479. 
FAMA, E. F., y French, K. R. 1988. Dividend yields and expected stock returns. Journal of Financial Economics 22: 3-27.

- 1989. Business conditions and expected returns on stocks and bonds. Journal of Financial Economics 25: 23-49.

- 1992. The cross-section of expected stocks returns. The Journal of Finance 47: 427-465.

- 1993. Common risk factors in the returns on stoks and bonds. Journal of Financial Economics 33 (1): 3-56.

- 1998. Value versus growth: The international evidence. The Journal of Finance 53 (6): 1.9751999.

FAma, E. F., y MacBeth, J. D. 1973. Risk, return, and equilibrium: Empirical tests. Journal of Political Economy 81: 607-636.

Ferson, W.E., y Harvey, C.R. 1991. The variation of economic risk premiums. Journal of Political Economics 99: 385-415.

- 1999. Conditioning variables and cross-section of stock returns. The Journal of Finance 54: 1.325-1.360.

FonT, B., y GRAU, A. J. 2007. Los factores tamaño, book-to market y momentum en el mercado de capitales español: explicaciones racionales en la formación del precio. Revista Española de Financiación y Contabilidad 36: 509-536.

- 2009. ¿Cómo se valoran las acciones españolas: en el mercado de capitales doméstico o en un mercado europeo? Moneda y Crédito 229: 91-156.

Forner, C., y Marhuenda, J. 2003. Contrarian and momentum strategies in the Spanish stock market. European Financial Management 9: 67-88.

- 2006. Análisis del origen de los beneficios del momentum en el mercado de valores español. Investigaciones Económicas 30: 401-439.

Forner, C.; Sanabria, S., y Marhuenda, J. 2009. Post-earnings announcement drift: Spanish evidence. Spanish Economic Review 11: 207-241.

Gibbons, M. R. 1982. Multivariate test of financial models. A new approach. Journal of Financial Economics 10: 3-27.

GonzÁlez, E., y Ventura, J. 2007. Variedad estratégica y rentabilidad empresarial. Revista de Economía Aplicada 43: 71-94.

HANSEN, L.P., y Singleton, K. J. 1982. Generalized intrumental variables estimation of nonlinear rational expectations models. Econometrica 50( 5): 1.269-1.286.

Hawawini, G., y Keim, D. 1995. On the predictability of common stock returns: World-wide evidence. In R. Jarrow, V. Maksimovic y W. Ziembra (eds.) North-Holland: Handbook in Operations Research and Management Science 9.

JAGAnNAThan, R., y WANG, Z. 1996. The conditional CAPM and the cross-section of expected returns. The Journal of Finance 51: 3-53.

MenÉndez, S. 2000. Determinantes fundamentales de la rentabilidad de las acciones. Revista Española de Financiación y Contabilidad 29 (106): 1.015-1.031.

Miralles, J. L., y Miralles M. M. 2003. Actividad negociadora y esperanza de rentabilidad en la bolsa de valores española. Revista Economía Financiera 1: 15-36.

Moskowitz, T. J., y Grinblatt, M. 1999. Do industries explain momentum?. The Journal of Finance 54(4): 1.249-1.290.

NeWEy, W., y WeSt K. 1987. A simple positive semi-definite, Heteroskedasticity and autocorrelation consistent covariance matrix. Econometrica 55: 703-708.

Nieto, B. 2002. La valoración intertemporal de activos: un análisis empírico para el mercado español de valores. Investigaciones Económicas 26: 497-524. 
NiETo, B. 2004. Evaluating multi-beta pricing models: An Empirical analysis with Spanish market Data. Revista Economía Financiera 2: 80-108.

Nieto, B., y Rubio, G. 2002. El modelo de valoración con cartera de mercado: una nueva especificación del coeficiente beta. Revista Española de Financiación y Contabilidad 31 (113): 697-723.

Nieto, B., y Rodríguez, R. 2005. Modelos de valoración de activos condicionales: un panorama comparativo. Investigaciones Económicas 29 (1): 33-71.

Rodríguez, J.; Álvarez, A.; Arias, C., y Fernández, E. 2009. La contribución de las infraestructuras a la producción: estimación por máxima entropía. Revista de Economía Aplicada 50: 77-96.

Rubio, G. 1988. Further international evidence on asset pricing: The case of the Spanish capital market. Journal of Banking and Finance 12: 221-242.

Stattman, D. 1980. Book values and stock returns. The Chicago MBA: A Journal of Selected Papers 4: 25-45.

VASSAlou, M. y APEDJinou, K. 2004. Corporate innovation, price momentum, and equity returns, Working Paper, Columbia University. Disponible en http://ssrn.com/abstract=66336/ [aceso 15 de mayo de 2010].

White, H. 1980. A heteroskedasticity-consistent covariance matrix and a direct test for heteroskedasticity. Econometrica 48: 817-838. 
